\title{
A 3D unstructured-grid model for Chesapeake Bay: importance of bathymetry
}

\author{
Fei Ye \\ Virginia Institute of Marine Science, feiye@vims.edu \\ Yinglong J. Zhang \\ Virginia Institute of Marine Science, yjzhang@vims.edu \\ Harry V. Wang \\ Virginia Institute of Marine Science, wang@vims.edu \\ Marjorie A.M. Friedrichs \\ Virginia Institute of Marine Science, marjy@vims.edu \\ Isaac D. Irby \\ Virginia Institute of Marine Science, iirby@vims.edu
}

See next page for additional authors

Follow this and additional works at: https://scholarworks.wm.edu/vimsarticles

Part of the Oceanography and Atmospheric Sciences and Meteorology Commons

\section{Recommended Citation}

Fei Ye, Yinglong J. Zhang , Harry V. Wang , Marjorie A.M. Friedrichs , Isaac D. Irby , Eli Alteljevich , Arnoldo Valle-Levinson, Zhengui Wang, Hai Huang, Jian Shen, Jiabi Du , A 3D unstructured-grid model for Chesapeake Bay: importance of bathymetry, Ocean Modelling (2018), doi: 10.1016/j.ocemod.2018.05.002

This Article is brought to you for free and open access by W\&M ScholarWorks. It has been accepted for inclusion in VIMS Articles by an authorized administrator of W\&M ScholarWorks. For more information, please contact scholarworks@wm.edu. 


\section{Authors}

Fei Ye, Yinglong J. Zhang, Harry V. Wang, Marjorie A.M. Friedrichs, Isaac D. Irby, Eli Alteljevich, Arnaldo Valle-Levinson, Zhengui Wang, Hai Huang, Jian Shen, and Jiabi Du 
A 3D unstructured-grid model for Chesapeake Bay: importance of bathymetry

Fei Ye, Yinglong J. Zhang, Harry V. Wang, Marjorie A.M. Friedrichs, Isaac D. Irby, Eli Alteljevich , Arnoldo Valle-Levinson, Zhengui Wang, Hai Huang, Jian Shen, Jiabi Du

PII: S1463-5003(18)30156-2

DOI: 10.1016/j.ocemod.2018.05.002

Reference: OCEMOD 1308

To appear in:

Ocean Modelling

Received date: $\quad 6$ January 2018

Revised date: $\quad 26$ March 2018

Accepted date: 4 May 2018

Please cite this article as: Fei Ye, Yinglong J. Zhang, Harry V. Wang, Marjorie A.M. Friedrichs, Isaac D. Irby , Eli Alteljevich, Arnoldo Valle-Levinson, Zhengui Wang, Hai Huang, Jian Shen, Jiabi Du , A 3D unstructured-grid model for Chesapeake Bay: importance of bathymetry, Ocean Modelling (2018), doi: 10.1016/j.ocemod.2018.05.002

This is a PDF file of an unedited manuscript that has been accepted for publication. As a service to our customers we are providing this early version of the manuscript. The manuscript will undergo copyediting, typesetting, and review of the resulting proof before it is published in its final form. Please note that during the production process errors may be discovered which could affect the content, and all legal disclaimers that apply to the journal pertain. 


\section{Highlights}

- Complex physical processes in Chesapeake Bay and the adjacent shelf are investigated by a cross-scale baroclinic model.

- Recently developed techniques are applied, including a flexible vertical grid system, an implicit transport solver, etc.

- Good model skills are achieved with the techniques mentioned above and an accurate representation of bathymetry.

- The importance of bathymetry for estuarine modeling and the effect of bathymetry smoothing are discussed quantitatively. 


\section{A 3D unstructured-grid model for Chesapeake Bay: importance of bathymetry}

Fei Ye ${ }^{\mathrm{a}}$, Yinglong J. Zhang ${ }^{\mathrm{a}}$, Harry V. Wang ${ }^{\mathrm{a}}$, Marjorie A.M. Friedrichs ${ }^{\mathrm{a}}$, Isaac D. Irby ${ }^{\mathrm{a}}$, Eli Alteljevich $^{\mathrm{b}}$, Arnoldo Valle-Levinson ${ }^{\mathrm{c}}$, Zhengui Wang ${ }^{\mathrm{a}}$, Hai Huang ${ }^{\mathrm{d}}$, Jian Shen ${ }^{\mathrm{a}}$, Jiabi Du ${ }^{\mathrm{a}}$

a. Virginia Institute of Marine Science,

College of William \& Mary,

1375 Greate Road,

Gloucester Point, VA 23062,

USA

b. California Department of Water Resource,

Sacramento, CA 95814

c. Univ. of Florida, Civil and Coastal Engineering Department

365 Weil Hall, PO Box 116580

Gainesville, FL 32611-6580

d. Tsinghua Univ., Beijing, China

Resubmitted to Ocean Modelling in March 2018

* Corresponding author; e-mail: yjzhang@vims.edu; phone: (804) 684-7466; fax: (804) 684-7179. 


\begin{abstract}
We extend the 3D unstructured-grid model previously developed for the Upper Chesapeake Bay to cover the entire Bay and its adjacent shelf, and assess its skill in simulating saltwater intrusion and the coastal plume. Recently developed techniques, including a flexible vertical grid system and a $2^{\text {nd }}$-order, monotone and implicit transport solver are critical in súccessfully capturing the baroclinic responses. Most importantly, good accuracy is achieved through an accurate representation of the underlying bathymetry, without any smoothing. The model in general exhibits a good skill for all hydrodynamic variables: the averaged root-mean-square errors (RMSE's) in the Bay are $9 \mathrm{~cm}$ for sub-tidal frequency elevation, $17 \mathrm{~cm} / \mathrm{s}$ for 3D velocity time series, 1.5 PSU and 1.9 PSU for surface and bottom salinity respectively, $1.1^{\circ} \mathrm{C}$ and $1.6{ }^{\circ} \mathrm{C}$ for surface and bottom temperature respectively. On the shelf, the average RMSE for the surface temperature is $1.4{ }^{\circ} \mathrm{C}$. We highlight, through results from sensitivity tests, the central role played by bathymetry in this estuarine system and the detrimental effects, from a common class of bathymetry smoothers, on volumetric and tracer fluxes as well as key processes such as the channel-shoal contrast in the estuary and plume propagation in the coast.
\end{abstract}

Keywords: bathymetry; cross-scale; SCHISM; estuarine circulation; Chesapeake Bay, USA

\title{
1 Introduction
}

Chesapeake Bay is a shallow drowned river valley in the Mid Atlantic Bight (MAB) and is the largest estuary in the continental USA. It provides essential ecological services to wildlife and to the local human population. As a result, Chesapeake Bay has stimulated a great deal of scientific research, on topics ranging from the physical processes (Goodrich et al., 1987; Sanford et al. 2001; Valle-Levinson et al., 2003; Scully et al., 2005), to eutrophication (Boesch et al., 2001; Cerco and Noel, 2004; Kemp et al., 2005), hypoxia (Officer et al., 1984; Bever et al., 2013; Du and Shen, 2015), nitrogen cycling (Feng et al. 2015) and the long-term trend of the above-mentioned processes under climate change (Hagy et al., 2004; Najjar et al., 2010; Murphy et al., 2011; Hong and Shen, 2012). In recent years, more and more emphasis has been placed on its productive tributaries and shallow regions, 
which have drawn particular interest from water quality and living resources management (Cerco et al., 2013). In other estuarine and coastal systems beyond Chesapeake Bay, there is also a universal need to investigate small-scale processes under large-scale remote forcing in a holistic manner (Brown and Ozretich, 2009; Möller et al., 2001; Gong and Shen, 2011).

Major challenges in simulating Chesapeake Bay include: (1) complex geometry and bathymetry with steep slopes at places; (2) large temporal variations in forcings (such as freshwater inputs and wind), which lead to highly variable stratification (from partially stratified under normal conditions to strongly stratified or mixed conditions during events) and unique circulation patterns (e.g., the 3-layer circulation) in some tributaries (Schubel and Pritchard, 1986; Goodrich et al., 1987); (3) complex linkages between the main stem dynamics and the small-scale processes occurring in the tributaries/sub-tributaries on one hand, and the large-scale processes in the coastal ocean such as the Gulf Stream (Ezer, 2013) on the other. These challenges require accurate representation of the underlying bathymetry, and set a high bar for model flexibility and efficiency in simulating cross-scale baroclinic processes. All of these are under-studied at the moment.

Previously, we have developed several new numérical techniques and incorporated them into a 3D unstructured-grid (UG) model (SCHISM, i.e., "Semi-implicit Cross-scale Hydroscience Integrated System Model"; Zhang et al., 2016a) and applied the model to the Upper Chesapeake Bay (Ye et al., 2016). With the newly introduced implicit transport solver with two total variation diminishing limiters $\left(\mathrm{TVD}^{2}\right)$, the model was shown to be able to accurately simulate saltwater intrusion and density stratification in the system, and can be readily extended into small tributaries and sub-tributaries. We continue previous work by extending the model to cover the entire Bay and a portion of the Mid Atlantic Bight (MAB) shelf. The rationale for including the shelf is to incorporate shelf processes as much as possible, because shelf and Bay processes are intertwined (Xu et al., 2011).

Several other models based on structured-grids (SGs) or UGs have been applied to the Bay (Li et al., 2005; Cerco et al., 2013; Lanerolle et al., 2011; Hong and Shen, 2012; Testa et al., 2014; Feng et al., 2015; Jiang and Xia, 2016) and an inter-comparison of some of these models can be found in Irby et al. (2016), who concluded that all models have similar skill in the deeper part of the Bay. Major departures of the current model from previous models are: (1) use of high-resolution hybrid triangular-quadrangular UG; (2) use of a novel hybrid vertical grid in order to seamlessly traverse contrasting spatial scales from sub-tributaries to 
shelf; (3) an implicit scheme that allows large time steps (in this case 2.5 minutes) in conjunction with high resolution for efficiency; (4) most importantly, an accurate representation of the original bathymetry through the combination of (1-2). Consequences from these choices are discussed and the detrimental effects of bathymetry smoothing is highlighted.

In the following sections, we first describe the observational datasets used in this paper (Section 2.1), and then provide a description of the model set-up (Sections 2.2 to 2.5). The model skill is then assessed in the Section 3. We then present a sensitiyity study on the importance of model representation of the underlying bathymetry (Section 4). Section 5 summarizes the paper.

\section{Methods}

\subsection{Observations used for model evaluation}

Chesapeake Bay and its adjacent shelf is a well-instrumented system with extensive in-situ and remote sensing observational assets. Environmental Protection Agency (EPA)'s Chesapeake Bay Program (CBP) Office maintains a network of stations and regularly conducts synoptic surveys throughout the Bay (usually bi-weekly in summer or monthly in winter); the measured variables include both physical and biogeochemical variables. The modeled salinity and temperature profiles will be compared to CBP observations.

$\mathrm{NOAA}^{\mathrm{a}}$ maintains over 40 tide gauges in and around the Bay and adjacent shelf, some of which will be used in mødel validation (Figure 1). In addition, PORTS ${ }^{\mathrm{b}}$ also maintains ADCPs at a few stations in the Bay during some recent years (Figure 1); the velocity data will be used to validate our modeled current profiles.

To maximize data availability, the model assessment in the main text focuses on the skill inside Chesapeake Bay during recent years (2011-2014); while the model performance in the plume region and on the shelf are briefly discussed in Appendix A for completeness. Appendix A2 assesses model results in the plume region, using the dataset collected during a 1996 (wettest year in recent history) survey (Valle-Levinson et al., 2007). Appendix A3 evaluates the model skill on the shelf, using a daily global 1-km operational Sea Surface

a url: https://tidesandcurrents.noaa.gov/tide_predictions.html/, last accessed in April 2017.

${ }^{\mathrm{b}}$ url: https://tidesandcurrents.noaa.gov/ports.html, last accessed in April 2017. 
Temperature $\left(\mathrm{G}_{\mathrm{SST}} \mathrm{c}\right)$ product based on satellite data, where various sea surface temperature (SST)datasets at different spatial resolutions are combined with a multi-scale twodimensional variational (MS-2DVAR) blending algorithm (Chao et al. 2009). Although G1SST is used as "observation" in this paper, it actually represents an optimal estimate of skin SST, whereas the modeled SST is a bulk estimate at the sea surface. All observational assets used in this paper (including those in the appendix) are summarized in Figure 1

\subsection{Numerical model}

The model SCHISM (Zhang et al., 2016a; Ye et al., 2016) is a derivative product of SELFE v3.1dc (Zhang and Baptista, 2008), but freely distributed using an Apache v2 license. It is an open-source community-supported modeling system, based on mixed triangularquadrangular unstructured grids in the horizontal and a very flexible coordinate system (Localized Sigma Coordinates with Shaved Cell, or LSC) in the vertical (Zhang et al., 2015), designed for the effective simulation of 3D baroclinic circulation across creek-to-ocean scales (Zhang et al., 2016a; Yu et al. 2017). The model employs a semi-implicit finiteelement/finite-volume method, together with an Eulerian-Lagrangian method (ELM; Baptista 1987) for momentum advection, to solve the Navier-Stokes equations in its hydrostatic form. As a result, numerical stability is greatly enhanced and the errors from the "mode splitting" method are avoided; in fact, the only stability constraints are related to the explicit treatment of the horizontal viscosity and baroclinic pressure gradient, which are much milder than the stringent Courant-Friedrichs-Lewy (CFL) condition. The implicit scheme used in SCHISM, originally pioneered by Richtmyer (1957) and Kwizak and Robert (1971) and popularized by Casulli and Cattani (1994), often allows the selective use of "hyper resolution" (on the order of a few meters) with little penalty on the time step. More information about the model and its application cases around the world can be found at www.schism.wiki (last accessed in March 2018). The version of SCHISM used in this paper is the publicly released tag version v5.3.1, freely downloadable at www.schism.wiki (last accessed in Jan 2018). We use this public version and upload some key files as supplementary materials (doi:10.21220/V5HK5S) to promote reproducibility of the results.

As an implicit model, SCHISM does not have a formal upper limit for time step, but in practice has an operating range on a fixed grid due to the accuracy consideration (in particular,

c url: https://podaac.jpl.nasa.gov/dataset/JPL_OUROCEAN-L4UHfnd-GLOB-G1SST, last accessed in April 2017. 
the scheme reduces to $1^{\text {st }}$-order accuracy with large time steps). The operating range for baroclinic applications is usually 100-200s. In the current case, the model results are relatively insensitive to the time steps $\Delta t$ between 100-150s, while with $\Delta t \geq 180$ s the model results would lead to larger vertical mixing and less stratification. The implicit scheme introduces some inherent numerical diffusion but this is balanced by the numerical dispersion inherent in the finite-element solver, as the latter effectively acts as an anti-diffusion. This balance is desirable as both diffusion and dispersion are detrimental to accuracy. Various higher-order schemes for the momentum and transport equations have been developed in recent years to further reduce the numerical diffusion, which is critical for applications in the large-scale eddying regime (Zhang et al. 2016a; Ye et al. 2016; Yu et al. 2017). The volume conservation in SCHISM is enforced by a finite-volume solver of the $3 \mathrm{D}$ continuity equation and mass conservation is enforced by a finite-volume solver of the transport equation; the former ensures the consistency (and often monotonicity) of the tracer solution. The use of a hybrid vertical gridding system $\left(\mathrm{LSC}^{2}\right)$ and a cubic spline Z-method in evaluating the pressure gradient greatly reduces the Pressure Gradient Error (PGE) as well as diapycnal mixing (Zhang et al. 2015).

\subsection{Digital Elevation Model (DEM) and bathymetry}

There are multiple publicly available DEMs for Chesapeake Bay and the adjacent shelf region. The DEM used here is primarily based on the topo-bathymetric information from USGS $^{\mathrm{d}}$, supplemented by the latest navigation charts ${ }^{\mathrm{e}}$, and coastal relief model ${ }^{\mathrm{f}}$ for the coastal and shelf region. Bathymetric changes due to regular dredging by USACE are not explicitly accounted for, but are treated as part of the model uncertainties. Since our grid resolution is much coarser than the original USGS DEM's $1 \mathrm{~m}$ resolution ${ }^{\mathrm{g}}$, the DEM was subsampled to $23 \mathrm{~m}$ in the north-south direction (mostly along-channel) and $18 \mathrm{~m}$ in the east-west direction (mostly cross-channel) to reduce its size. A locally volume conservative approach was adopted, with the elevation at each subsampled point being the average of all its neighboring points within the $23 \mathrm{~m} \times 18 \mathrm{~m}$ box in the original DEM in order to locally conserve volume. In an effort to easily incorporate new DEMs in small tributaries and sub-tributaries in the future,

${ }^{\mathrm{d}}$ url: https://topotools.cr.usgs.gov/coned/chesapeake_bay.php; last accessed in Feb. 2017.

${ }^{\mathrm{e}}$ Chesapeake Bay Maryland \& Virginia Chartbook (8th Edition), published by ADC The Map People, 2004.

${ }^{\mathrm{f}}$ url: https://www.ngdc.noaa.gov/mgg/coastal/crm.html, last accessed in Jan 2017.

${ }^{\mathrm{g}}$ The $1-\mathrm{m}$ resolution is used in the published USGS product, which is interpolated from original bathymetric survey data that often has much coarser resolution. 
we have triangulated the original raster files to generate an UG DEM (Figure 2), which can be found in the supplementary materials (doi:10.21220/V5HK5S).

The bathymetry in the Bay has several key features. There is a main shipping channel ( 15-40 m depth) that cuts through the otherwise shallow estuary and extends from the Atlantic Ocean to the Baltimore harbor. The channel is regularly dredged and maintained to make it navigable by megaships. Still, the channel cuts through shallow shoals in places (e.g. Figure 2c). It also branches off into multi-channel configuration at other places (Figure 2ad). As will be shown in Section 4, the channel-side slopes often exceed 1:2. The channel width varies from $\sim 5 \mathrm{~km}$ near the entrance to $\sim 400 \mathrm{~m}$ near Baltimore harbor (Figure 2a). The channel also turns abruptly at places (Figure 2acd), which is conducive to secondary circulation (Pein et al. 2014). Adequate bathymetric resolution is required to capture those channel constrictions (Figure 2acd), which have important implications for hydrodynamic processes in the Bay.

\subsection{Grid generation}

Our computational grid covers the entire Bay from Cape Henry to the Conowingo Dam in the Susquehanna River. The opening to Delaware Bay through the Chesapeake \& Delaware canal is closed in the grid since the dynamics there are generally believed to be insignificant for main Bay processes; preliminary test results support this hypothesis, though more carefully controlled tests are needed in the future. The grid also covers a portion of the MAB, up to Lewes, DE in the north and Beaufort Inlet, $\mathrm{NC}$ in the south, and out to the $3 \mathrm{~km}$ isobath (slightly beyond the shelf break) offshore. The inclusion of the shelf allows us to avoid significant influence from the boundary condition (B.C.) imposed there. Since the domain includes part of the Gulf Stream, we rely on the B.C. from the data-assimilated $\mathrm{HYCOM}^{\mathrm{h}}$ to bring its signal into the domain.

Due to its semi-implicit numerical algorithm and specific horizontal and vertical grid systems, SCHISM often incurs little penalty on time steps with fine resolution, so relative to prior modeling efforts in this domain, we can faithfully represent many key features (channels, shelf breaks, jetties, etc.). For example, finer resolution in the shipping channel (as compared to the shoals) is usually needed to accurately capture the saltwater intrusion process; however, refining deeper rather than shallow areas would run contrary to the requirements

h url: https://hycom.org/. 2011-2012: HYCOM + NCODA Global 1/12 ${ }^{\circ}$ Reanalysis (experiment 19.1); 2013-2014: HYCOM + NCODA Global 1/12 ${ }^{\circ}$ Analysis (experiment 90.9-91.1). 
arising from the CFL condition for explicit models. Additionally, the SCHISM formulation is very tolerant to skew elements, which helps us align the mesh to contours and breaks. Figure 3 is a map showing contours that are enforced as part of our grid generation process (excerpted from the "map" file from SMS software'). The channel edges (based on the highest gradient of the isobaths) and shelf break are captured by carefully aligning element edges to these features. Often the channel profile is represented by at least 4 nodes, with 2 nodes dispensed to represent each channel edge (one at the top and the other at the foot of the edge; Figure 3c). Meshing in this way causes the feature-aligned arcs to be close to each other on steep channel slopes (Figure 3ab), resulting in skew elements, but the implicit model can deal with elements with the skewness (defined as the ratio between the maximum side length and the equivalent diameter of an element) exceeding 20. Admittedly, skew elements degrade accuracy locally and therefore smoother transition would be required to achieve better accuracy, at the expense of efficiency. Once the important features to be aligned have been digitized, the hybrid triangular-quad grid is generated. The grid resolution is primarily controlled by the arc resolution. The final computational grid has 28,137 nodes, 35,756 triangles and 8,833 quads (Figure 4). Besides reducing the number of grid elements and thus the computational cost, the use of quads in the channelized areas in a flow-aligned fashion was also deemed beneficial for channelized flow (Holleman et al. 2013).

Mesh bottom elevations for the present model are populated by a linear interpolation from the DEM. Such a method is consistent with the linear shape function used in the finiteelement framework in SCHISM. The use of shaved cells near the bottom ensures a smooth and continuous representation of the bottom. Although the combined procedure is 2nd-order in its representation of bottom, if the mesh is not sufficiently resolved it can lead to systematic loss of volume in convex channels - a small amount of such loss can be seen in Figure $3 \mathrm{c}$ as the region between the linear bottom and the "true" bed. Importantly, the mesh is not smoothed. We later perform sensitivity studies on bathymetry smoothing, which is often used by terrain-following coordinate models. The implication of the smoothing procedure will be discussed in Section 4.

The model uses the new flexible vertical grid system LSC $^{2}$ (Localized Sigma Coordinates with Shaved Cells) developed by Zhang et al. (2015), which is a generalization of the Vanishing Quasi-Sigma Coordinates of Dukhovskoy et al. (2009). The number of layers

\footnotetext{
i url: aquaveo.com, last accessed in Jan 2017.
} 
changes with depth, which leads to a much milder coordinate slope (e.g., the near-horizontal layers in Figure 5e) than that of the pure terrain-following coordinate grid. As a result, pressure gradient error as well as the spurious diapycnal mixing are reduced (Zhang et al., 2015). To ensure a smooth (piece-wise linear) staircase-free bottom representation, shaved cells are added near the bottom, which has been demonstrated to be essential for successfully capturing the bottom controlled processes such as saltwater intrusion (Ye et al. 2016) and dense water overflow along steep slopes (Zhang et al., 2016ab; Stanev et al., 2017), and also help reduce the unphysical diapycnal mixing (Zhang et al. 2015). The number of levels in the final vertical grid varies from 16 (at $8 \mathrm{~m}$ depth) to 67 (at $4000 \mathrm{~m}$ depth), and 24.6 on average. Figure 5 shows typical configurations of the vertical grid in and outside the Bay. High resolution is applied near the surface and bottom, but the mid depths inside the Bay are also adequately resolved in order to capture the sharp pycnocline there. In generating the vertical grid, we have used two master grids (see Zhang et al., 2015 for more details on master grids), designed for the Bay and shelf portions of the domain respectiyely and "stitched" together at a common depth near the Bay entrance (Figure $5 \mathrm{bc}$ ). The flexibility afforded by $\mathrm{LSC}^{2}$ allows us to apply resolution almost at will (as each horizontal node can have its own vertical grid), although abrupt transitions in the number of levels should be avoided in practice as they may lead to excessive momentum dissipation.

\subsection{Model setup}

The primary simulation period of 2011-2014 includes some typical variability of the hydrological flow regime: a wet year in 2011, a dry year in 2012 (with a below-average spring freshet), average years in 2013 and 2014, and three major storms (Hurricane Irene in Aug. 2011, Tropical Storm Lee in Sept. 2011, and Hurricane Sandy in Oct 2012) (Figure 6a). In addition, we also present in Appendix A2 an extreme case of a strong El Nino year (1996) with large freshets (Figure 6b). To more accurately simulate the salinity in the Bay we opted to use the watershed loadings calculated from CBP's watershed model (Shenk and Linker, 2013) for years 2011-2014; we found that the results from this approach were slightly more accurate than those using the river flows at the seven major tributaries (Susquehanna, Patuxent, Potomac, Rappahannock, Pamunkey, Mattaponi, and James) as measured by USGS gauges, suggesting influence from smaller tributaries may not always be negligible. The total amount of fresh water flows into the Bay from the two approaches are generally similar but sometimes differ significantly (Figure 6a), especially during autumn and winter, when the 
total flow from the watershed model is often larger. The watershed model loadings include the inflows from smaller tributaries and sub-tributaries, whose effects are locally very important.

A hybrid wind dataset blending North American Regional Reanalysis (NARR) and NDBC buoy observations is generated using the simple method proposed by Lanerolle et al. (2011). Compared to Lanerolle et al. (2011)'s early work, more NDBC buoys are available in the primary simulation period and are incorporated into the hybrid wind product, providing a more extensive coverage inside the Bay (see supplementary materials). Compared to the pure NARR wind, the hybrid wind possesses more spatial/temporal variability and gusts. As shown in Ye et al. (2016), the use of the hybrid product leads to a more realistic windinduced mixing. Other atmospheric forcing applied at the surface is taken from NARR, including: atmospheric pressure (important during storms), downward short-wave and longwave radiation fluxes, air temperature, specific humidity. The effect of direct precipitation is also included but is found to be mostly negligible. The atmospheric forcing is then used to calculate the momentum and heat exchanges between the air and water via the bulk aerodynamic model of Zeng et al. (1998).

At the ocean boundary, the imposed elevation is interpolated from two tide gauges at Lewes, DE and Beaufort, NC, using the inverse distance interpolation method. The difference in phase/amplitude between each boundary point and the two tide gauges are also considered, based on the result of a 2D barotropic SCHISM model on a larger grid that encompasses the entire east coast of US. This approach ensures that both tidal and sub-tidal frequency signals are incorporated in the model. The horizontal velocity B.C. is a linear superimposition of a tidal component generated by the large-domain 2D barotropic SCHISM model and a nontidal component from the daily outputs from HYCOM. The salinity B.C. is interpolated from the monthly climatology of World Ocean Atlas $2001^{\mathrm{j}}$. The temperature B.C., on the other hand, is interpolated from HYCOM to better account for inter-annual variability for this variable. In addition, the simulated salinity and temperature are also relaxed towards climatology/HYCOM respectively in a region $\sim 30 \mathrm{~km}$ near the ocean boundary, with a maximum temporal relaxation scale of 0.5 days, in order to prevent long-term drift. The relaxation constant decreases linearly from its maximum value at the ocean boundary to 0 at $\sim 30 \mathrm{~km}$ from the boundary. A sensitivity run (cf. Table 1) with HYCOM as salinity B.C.

j url: http://www.nodc.noaa.gov/OC5/WOA01/pr_woa01.html, last accessed in Jan 2017 
yielded mostly similar results but with occasional larger errors at the Bay entrance (not shown), which is likely due to errors in the HYCOM salinity.

Initially the water is at rest. The initial 3D salinity/temperature field inside the Bay is interpolated from the observations at CBP Water Quality Monitoring stations along the main shipping channel (Figure 1): salinity and temperature are first interpolated along the longitudinal transect, and then laterally extrapolated in the cross-channel direction at each depth. The initial temperature and salinity on the shelf are interpolated from $\mathrm{HYCOM} /$ climatology respectively.

The model uses a non-split time step of $150 \mathrm{~s}$ (which is sufficient to resolve most transient hydrostatic processes), the implicitness factor of 0.6 , and turbulence closure of $k-k l$ (Umlauf and Burchard, 2003). A uniform drag coefficient of 0.0025 is applied at the bottom grid cell for simplicity. The momentum advection is solved by a $2^{\text {nd }}$-order scheme with a Shapiro filter (MB-LI; see more details in Zhang et al., 2016a). No explicit horizontal viscosity or diffusivity is applied in the model; note that the higher-order $\mathrm{TVD}^{2}$ transport solver is monotone by design (Ye et al., 2016). Since the mean residence time in the modeled region is about 3 months estimated from an average flow year (Hong and Shen, 2012) and at most 6 months in the dry period (Du and Shen, 2016), the model is initialized 6 months before the periods of interest. On 48 Intel XEON cores of the Sciclone cluster at College of William \& Mary, the model runs 405 times faster than real time. Table 1 summarizes the outcome from more than 200 sensitiyity runs with respect to model parameters.

\section{Model assessment}

Consistent with Ye et al. (2016), we use standard statistics to assess model errors against observation, including: RMSE (Root Mean Square Error), MAE (Mean Absolute Error), bias and $\mathrm{CC}$ (correlation coefficient). The simulated elevation is compared to observation at 8 NOAA stations from the coastal region to the inside of the Bay. The simulated velocity is compared to the multi-layer ADCP measurements at 3 locations from the Bay mouth to the upper Bay. The overall salinity and temperature skill is based on an ensemble in space (at 39 CBP Water Quality Monitoring stations in the Bay; Figure 1). The bias and RMSE between the model and observations are summarized in the form of target diagram (Figure 7). Each variable is normalized to the standard deviation of the corresponding observation type so as to compare multiple variables on a single plot. In the target diagram, the $x$-axis is defined 
such that $x>0$ indicates an over-estimation in the variability of the observations and $x<0$ indicates an under-estimation, whereas $y>0$ indicates an over-estimation in the mean of the observations and $y<0$ indicates an under-estimation. More details on these diagrams are described by Hofmann et al. (2008) and Jolliff et al. (2009).

The presentation of individual results will be focused more on salinity given its importance for density stratification. Most stations shown are in the main stem of the Bay; model assessment in the tributaries has been discussed elsewhere (Ye et al. 2016).

\subsection{Elevation}

Both sub-tidal and tidal frequency signals at NOAA tide gauges are compared to the SCHISM output. In general, the modeled free-surface elevation agrees well with the observations. For the subtidal elevation, the averaged RMSE and Correlation Coefficient (CC) over all stations are $9 \mathrm{~cm}$ and 0.84 respectively. For the total elevation (including both tidal and sub-tidal frequencies), the averaged RMSE and CC over all stations are $11 \mathrm{~cm}$ and 0.90 respectively. The hurricane induced set-ups are also captured by the model (e.g., Hurricane Irene in Figure 8).

The amplitudes and phases of the major constituents are captured as shown by the harmonic analysis (Figure 9); the largest error for the M2 amplitude is only $1.8 \mathrm{~cm}$, and 3.9 degrees for the M2 phase. The model tends to over-estimate the amplitudes except at Station Annapolis, where the largest error happens to occur (Figure 9). Station Annapolis is near the semi-diurnal nodal area and its M2 amplitude is smaller than the two neighboring main stem stations (Station Solomons Island and Station Tolchester Beach), which is confirmed by the model results. Other constituents are also accurately simulated. The rapid decrease of the M2 (and other constituents') amplitude from the lower to upper Bay indicates that the Bay is a highly dissipatiye system as discussed by Zhong et al. (2008).

\subsection{Velocity profile}

Three NOAA/PORTS ADCPs in the lower, mid and upper Bay (Figure 1) were operational in parts of 2012-2014, and the data are used to assess the vertical structure of the along-channel velocity. The barotropic velocities are primarily driven by tides, winds and pressure gradient set up by the river flows. The modeled barotropic velocity shows a reasonable skill (Figure 10). The averaged RMSE in 2012-2014 for all stations is $16 \mathrm{~cm} / \mathrm{s}$. 
Significant baroclinic effects are found at all stations due to persistent density stratification, and the model captures the mean baroclinic velocity structure reasonably well (Figure 11). Larger errors are found near bottom at the two upper Bay stations cb1101 and cb1201, partly due to the uncertainties in bathymetry (as the channel is regularly dredged in this region). Overall, the averaged CC's at the three stations are $0.89,0.88$, and 0.92 respectively, and the averaged RMSE's (which include some small phase errors) are 21,15 , and $13 \mathrm{~cm} / \mathrm{s}$ respectively, or $17 \mathrm{~cm} / \mathrm{s}$ overall for 3D velocity time series. Since the RMSE is $16 \mathrm{~cm} / \mathrm{s}$ for the barotropic velocity, the main error source is of barotropic origin (more precisely, the small phase error).

\subsection{Model skill for salinity and temperature}

The performance of our model (Figure 7) is similar to EPA's regulatory model CH3D (cf. Figure $8 \mathrm{a}$ in Irby et al., 2016). The surface temperature is particularly well simulated, followed by the bottom temperature. The errors associated with salinity are smaller than other models shown in Irby et al. (2016). The maximum vertical gradient is on average slightly under-predicted and the depth of the max gradient is over-predicted; the variability of these quantities are also under-predicted. It is not surprising that the stratification indicators (as derived variables) have lower skills than the bottom/surface values. The vertical profiles (especially for salinity) are challenging to capture, as the stratification in the micro-tidal Chesapeake Bay has large temporal variations, primarily due to the seasonally-varying fresh water inputs (Schubel and Pritchard, 1986) and wind mixing (Goodrich et al., 1987). The model captures these temporal variations reasonably well (cf. the observation and "Baseline" model results in Figure 15 and also Appendix A1). The vertical salinity profiles at all observation stations during the main simulation period can be found in the supplemental material (doi: 10.21220/V5HK5S). The RMSE's for all 3D salinity profiles are $1.8 \mathrm{PSU}$ overall: 1.9 PSU for bottom salinity, and 1.5 PSU for surface salinity. The corresponding numbers for temperature are $1.4{ }^{\circ} \mathrm{C}, 1.6^{\circ} \mathrm{C}$, and $1.1^{\circ} \mathrm{C}$.

We have also calculated the statistics for salinity and temperature in each year, and in the main channel and shallow shoals separately; the results are similar to those shown in Figure 7. This suggests the model is capable of resolving temporal and spatial variabilities in these variables. Additionally, a transect along the main channel provides a more detailed view of the spatially variable, yearly averaged salinity structure (Figure 12). The model generally captures the stratification structure and longitudinal salt transport well, with a small under- 
estimation at some lower Bay stations (e.g. CB7.4); an over-estimation of stratification in the mid-bay is also visible in 2012. In general, the model captures well the spatial variability of stratification, including the local minimum near CB7.1S and CB5.5, and the largest stratification at $\mathrm{CB} 3.3 \mathrm{C}$. The maximum stratification at $\mathrm{CB} 3.3 \mathrm{C}$ is due to its proximity to the freshwater zone and large depth $(26 \mathrm{~m})$ locally, and is generally modeled well.

For brevity, more detailed comparisons including those in the shelf area are presented in Appendix A.

\section{Importance of bathymetry}

Numerous sensitivity tests conducted with SCHISM (cf. Table 1) indicate that the high model skill is primarily attributed to (1) accurate representation of the bathymetry, particularly the channel profile, by the hybrid horizontal and vertical grids; (2) higher-order numerical methods developed in recent years (Zhang et al., 2016a; Ye et al., 2016). The importance of (1) will be explained in this section.

One of the most fundamental forcings in the shallow water regime is the underlying bathymetry. While the importance of bathymetry in a numerical model is widely accepted, the ideal is often compromised in practice. The reasons vary but here we distinguish two types of errors:

a) Type I: representational errors due to bad values or the finite, discrete representation of the domain. Discretization will always result in errors in the representation of water depths and volume. There can be also be ambiguity over which quantities (point values or moments like face areas and volumes) are of higher priority and whether features like bed forms should be treated as subgrid and modeled with closures or explicitly resolved.

b) Type II: errors and adjustments harking back to artifacts of numerical models, including requirements for stability, accuracy or efficiency. These adjustments are often mandatory, in which case their deleterious effects may not be testable in a simple way.

Horizontal resolution is a remedy for many geometry-related issues, but any refinement below the scales of physical interest usually represents a computational expense that is hard to accept. Smoothing is also used in addressing bathymetry-related issues, although the role it 
plays is different for the two types of errors enumerated above. An example involving representational difficulties (Type I error) would be the removal of small bathymetric features to avoid aliasing them on a coarser grid. The smoothing in this case may be coupled with a moment-preserving constraint such as volume preservation. Figure 13 shows an example taken from Liberty Island, an intertidal island in the Sacramento-San Joaquin Delta in California. The small-scale "moonscape" in this DEM arises mostly because of difficulties with bathymetry collection in a shallow, turbid and vegetated environment. The filtering algorithm used in (b) is due to Mallidi and Sethian (1996), based on an anisotropic curvature flow originally designed to de-noise features in medical images. This preprocessing step eliminates curvature below a specified length scale (in this case $20 \mathrm{~m}$ ), but preserves steep slopes, peaks and valleys. Using a Nyquist analog as a rough guide, convergence in this case would be straightforward at scales from $40 \mathrm{~m}$ down to $10 \mathrm{~m}$, any further refinement in the mesh would have to be reconciled with the choice of length scale of the smoother and the rough quality of the underlying data.

More objectionable is the Type II case where bathymetry smoothing is required to make up for a shortcoming such as PGE in terrain-following coordinates, first discussed by Haney (1991). In this case, a smoother is used to limit the coordinate slope, and in doing so it alters the bed geometry in systematic ways. The effects of Type II errors have not been carefully assessed so far because models based on terrain-following coordinates often become unstable without smoothing. Since SCHISM uses terrain-following like coordinate but is stable over non-smoothed bathymetry, we can systematically assess the error and false physics generated by the altered bathymetry.

We demonstrate with the current application case how bathymetry smoothing changes the character of the geometry in a way that leads to system-wide changes in response. In the sensitivity tests, the original bathymetry is smoothed inside different regions of the Bay-Shelf model using the Hannah-Wright smoother (Hannah and Wright 1995) with $r=0.1$, which is a typical yalue applied in some terrain-following coordinate models (Hu and Wang, 2010; Khangaonkar et al., 2012). Similar conclusion can be drawn for any smoother that fulfills a similar function or with a larger $r$ value, as shown in Figure 18.

With the Hannah-Wright smoother, the depths at the vertices of each element are iteratively altered to satisfy the following criterion: 


$$
\frac{h_{\max }-h_{\min }}{h_{\min }} \leq r,
$$

or equivalently:

$$
h_{\max } \leq(1+r) h_{\min },
$$

where $h_{\max }$ and $h_{\min }$ are maximum and minimum depths in an element, and $r$ is a user prescribed threshold related to the Haney criterion (usually on the order of 0.1). Eq. (2) could therefore be satisfied with a sufficiently fine resolution, at least in theory. If this criterion is violated in an element, the $\max / \mathrm{min}$ depths are reduced/increased by an amount of $0.02 * h_{\max }$. The procedure conserves the original volume. The iteration continues until this criterion is satisfied by all elements, or the maximum depth change in two consecutive iterations is less than a prescribed threshold (e.g. $1 \mathrm{~m}$ ).

In the rest of this section, we present two sensitivity tests in which the original bathymetry is smoothed in the mid-Bay and the whole domain respectively.

\subsection{Local smoothing in a mid-Bay region}

In the first sensitivity test, a region in the mid-Bay is smoothed (Figure 14a). As the volume is conserved by the smoother, the deeper channel becomes shallower, and the shallower shoals are deepened, with large bottom slopes removed (Figure 14: b versus c). These lead to changes in terms of mixing patterns, partition in volume flux, lateral flow, and the location of pycnocline. The sequence of this list of variables does not imply a cause-effect relationship, since they are interrelated components in a non-linear system and all governed by the underlying bathymetry. It should be noted the location of pycnocline is of particular interest in water quality and biological studies, since it is closely related to the hypoxic volume (Bever et al., 2013).

The most jobvious change is seen in the mixing patterns (Figure 14bc). With the original bathymetry, large turbulence mixing is visible near the corners of the steep slope (Figure 14b); after smoothing, the mixing near the slope is reduced and the low mixing zone extends more into the shallows (the area highlighted by solid ellipses in Figure 14c). Note that the highmixing zone near the corners is, in all likelihood, physical, and its absence in the smoothed bathymetry fortuitously masks numerical dissipation by lowering the amount of physical mixing. Even though the smoothing is only done in a small region in the mid-Bay, its effect is felt farther up-estuary. With smoothing, the salinity at CB3.3C increases by 1.6 PSU on 
average, because the total mixing (i.e., the sum of physical and numerical mixings) is kept low by under-estimation of the physical mixing in the smoothed region. As a result, even low-order upwind scheme can apparently give 'reasonable' results for the averaged salinity, but not its 3D profile (because the original and altered depths do not even match). Therefore accurate simulation of such domains requires both accurate solvers (e.g., the higher-order schemes and the new $\mathrm{LSC}^{2}$ grid) and realistic, high-resolution bathymetry.

The bathymetry smoothing also affects the partition of volume flux. Although the total volume flux across the entire transect (from bank to bank in Figure 14a) does not change (i.e. $-1370 \mathrm{~m}^{3} / \mathrm{s}$ for both original and smoothed bathymetry, with negative values indicating seaward fluxes), the partitioning of fluxes between channel (the blue portion of the transect in Figure 14a) and shoal is altered as the channel volume is decreased and shoal volume is increased; the yearly averaged flux for the channel portion in 2012 is $74 \mathrm{~m}^{3} / \mathrm{s}$ (i.e. landward) for the original bathymetry and $-197 \mathrm{~m}^{3} / \mathrm{s}$ (i.e. seaward) for the smoothed bathymetry, and the remaining fluxes for the shoal portion are $-1444 \mathrm{~m}^{3} / \mathrm{s}$ and $-1173 \mathrm{~m}^{3} / \mathrm{s}$ respectively. In other words, the channel-shoal contrast is reduced with the smoothed bathymetry. Under the original bathymetry, the intrusion occurs more along the channel and less along the shoal, resulting in more seaward outflow in shallow depths.

More importantly, the change in lateral salinity distribution results in a reduction in volume below pycnocline (defined as the location of the largest vertical salinity gradient; Figure 14d). After smoothing, the bottom high salinity intrudes more onto the shoal and the position of the pycnocline shifts. These lead to a $23.8 \%$ reduction in the area (along this transect) below pycnocline on average (up to a maximum of $49.6 \%$ at times). In other words, the hypoxic volume could be systematically underestimated with bathymetry smoothing. A more holistic view on the hypoxic volume in the Bay will be discussed in the next sensitivity test.

Lastly, several changes in the circulation patterns after smoothing are also noticeable (Figure 14e): (1) the lateral flow on the eastern side of the transect (20-40 km on the $x$-axis) becomes more uniformly to the east; whereas more complex two-layer and even a three-layer exchange flows exist under the original bathymetry; (2) the lateral flow magnitude near the two land boundaries increases, which is likely due to the deepening of the shoal; (3) stronger exchanges occur near the channel slopes (near $14 \mathrm{~km}$ on the horizontal axis in Figure 14e) in the smoothed bathy; (4) longitudinal exchange flow is generally weakened (some surface 
flow near the two banks even changes the direction from seaward to landward ), with the core of the surface seaward flow moved on to the shoal. These suggest the cross-channel flow is highly regulated by the bathymetry; and bathymetry smoothing reduces channel-shoal contrast by artificially enhancing channel-shoal exchange.

The effects of bathymetry smoothing on accuracy is shown in Figure 15. In general, the smoothed bathymetry leads to over-intrusion and over-estimation of stratification, which is consistent with the reduced overall mixing in this case. Note that by re-calibrating the model with the smoothed bathymetry (e.g., reducing salinity intrusion by adding extra numerical diffusion), it is possible to get similar skills in the deep channel as the baseline, but it's impossible to get both channel and shoal right, as the altered channel-shoal contrast cannot be compensated. We therefore conclude that accurate simulation of nearshore systems requires both realistic, high-resolution bathymetry and accurate solvers

\subsection{Whole-domain smoothing}

In the second sensitivity test, we apply the same bathymetry smoother on the entire model domain and focus on the overall system-wide changes. The most obvious change is that the Bay becomes more stratified after smoothing (Figure 16); the bottom and surface salinity both increase, with larger increases near bottom (not shown). These are due to a more 'uniform' intrusion pattern along the channel and the shoal (cf. insets of Figure 16). As a result, bathymetry smoothing often 'helps' models with under-intrusion and understratification problems. However, since a first-order forcing (bathymetry) is altered to compensate errors in the simulated salinity etc., it is hard to reconcile it with other processes. For example, side channels should be fresher and less stratified than the main channel. This is captured by the model with original bathymetry; an evidence is that the model skill on salinity is similar between the main-channel and the shoal stations (cf. Figure A1 for cast comparisons in the main stem and shallow regions), suggesting the shear dispersion is properly captured. However, with the smoothed-bathymetry, although we could get a 'similar' intrusion in the main channel by using a lower-order transport scheme, the skill on side channel stations significantly deteriorates. This is because the channel-shoal difference in salinity is reduced and the model is no longer able to capture the spatial heterogeneity in the lateral salinity distribution. In the rest of this sub-section, we first examine the change in 
intrusion pattern by a salt budget analysis, followed by a discussion on its implications on other key variables.

\subsubsection{Salt budget}

Salt budget is analyzed on several cross-channel transects from the Bay mouth to the upper Bay. Following Lerczak et al. (2006)'s procedure, the total flux $F_{S}$ is defined as:

$$
F_{s}=\left\langle\int u s \mathrm{~d} A\right\rangle
$$

where the angular bracket denotes time averaging, $u$ is the velocity component perpendicular to the transect; $s$ is salinity; $A$ is cross-sectional area. For a generic variable $\phi$ (such as velocity and salinity), it can be decomposed into the cross-sectionally averaged subtidal component $\left(\phi_{0}\right)$, the cross-sectionally varying sub-tidal component $\left(\phi_{E}\right)$, and the crosssectionally varying and tidally varying component $\left(\phi_{T}\right)$ :

$$
\begin{gathered}
\phi_{0}=\frac{1}{A_{0}}\left\langle\int \phi \mathrm{d} A\right\rangle, \\
\phi_{E}=\left\langle\frac{h+\eta}{h} \phi\right\rangle-\phi_{0}, \\
\phi_{T}=\phi-\phi_{0}-\phi_{E},
\end{gathered}
$$

where $A_{0}$ is sub-tidal cross-sectional area; $h$ is bathymetry depth; $\eta$ is the tidally fluctuating surface elevation. Applying Eq. (4) on $u$ and $s$, Eq. (3) can be written as:

$$
\begin{gathered}
F_{s}=\left\langle\int\left(u_{0}+u_{E}+u_{T}\right)\left(s_{0}+s_{E}+s_{T}\right) \mathrm{d} A\right\rangle \\
\approx\left\langle\int\left(u_{0} s_{0}+u_{E} s_{E}+u_{T} s_{T}\right) \mathrm{d} A\right\rangle \equiv Q_{f} s_{0}+F_{E}+F_{T},
\end{gathered}
$$

where $Q_{f}$ includes the volume flux from both river discharge and Stokes transport and $Q_{f} S_{0}$ is the corresponding salt flux; $F_{E}$ is the salt flux from subtidal shear dispersion; and $F_{T}$ is the tidal oscillatory salt flux. The cross terms are neglected following Lerczak et al. (2006), due to their smaller magnitude. As shown in Figure 17, the differences in total salt flux $\left(F_{S}\right)$ between the two bathymetries grow rapidly from the mouth to the upper Bay, with a sign reversal at the mid- and upper-Bay transects. The flux decomposition shows that all components contribute to this discrepancy. In particular, $F_{E}$ is mostly larger (i.e. more up estuary) inside the Bay after smoothing, and the differences in $F_{T}$ become larger toward the 
upper Bay. Larger exchange flow resulted in stronger intrusion and larger stratification as shown above.

Since some terrain-following coordinate models can tolerate large $r$ values if the most dissipative option is used to stabilize the models (e.g., Sutherland et al., 2011), we have also included the results from $r=0.4$ in Figure 17. Although the agreement with the non-smoothed bathymetry is better than that in $r=0.1$, we still notice large discrepancies in the fluxes at most transects; in fact the averaged difference in total salt flux is $74 \%$.

\subsubsection{Hypoxic volume}

The averaged below-pycnocline volume in 2012 is reduced by $33.7 \%$ with the smoothed bathymetry, which is consistent with the results in Section 4.1. In addition, the distribution of this volume between channel and shoal is very different (cf, Figure 14d). This has significant implication for the estimate of summer hypoxia, which is a key parameter for the Bay management. Further study is warranted to look into how the bathymetry smoothing affects the severity and seasonal and inter-annual trends of the hypoxia.

\subsubsection{Plume extent}

We define the plume volume as the water volume outside the Bay mouth enclosed by the 30PSU iso-surface. The amount of freshwater outflow from up-estuary rivers is a key control for the extent of the Chesapeake Bay plume. In general, the freshwater outflow peaks in spring, but with considerable inter-annual variations in terms of magnitude and timing (Figure 6a). For example, large freshwater outflow was persistent from late 2011 to the beginning of 2012 (Figure 6a); as a result, the maximum plume volume in 2012 occurs in January (Figure 18a). Large differences (up to 52\%; Figure 18a) are found in plume volumes between the two sets of bathymetries. However, the monthly trend shows a more complex picture (Figure 18a). During the spring freshet, the plume is much larger on the smoothed bathymetry, whereas it is slightly smaller during the low-flow season (Figure 18a). In other words, the 'original' plume shows less variability. Not surprisingly, the large differences correspond to the large plume extent during freshet (Figure 18ab), when the exchange flow is strong. From the mass conservation point of view, a stronger salt intrusion (especially during freshets) under the smoothed bathymetry is compensated by a larger coastal plume, with a fresher bulge located farther offshore (Figure 18b). 


\subsection{DEM resolution}

Based on the two sensitivity tests above, we believe bathymetry smoothing (and in general Type II errors) should be avoided as much as possible, especially in estuarine/nearshore applications. Of course, many of our comments assume the availability of an elevation map of sufficient quality and resolution, usually much finer than the numerical grid. A coarser DEM causes feature loss analogous to that of isotropic smoothing. Fine-scale bathymetry, on the other hand, reveals steep bottom slopes as the grid is refined, exposing flow processes that may be of physical interest but also making it more difficult to satisfy the Haney criterion. We regard modeling these features as a positive thing, but there is one caveat that the continuous revelation of finer scales may at some point interfere with convergence, unless a length scale limitation is applied when extracting fine-scale features from the DEM. Since the processes of interest presented in this paper have spatial scale of $\sim 70 \mathrm{~m}$ or coarser, it is then justifiable to use a resolution of $\sim 23 \mathrm{~m}$ for the DEM.

\section{Conclusions}

We have successfully applied a 3D baroćlinic unstructured-grid model to Chesapeake Bay and the adjacent continental shelf. Recently developed new methods (TVD ${ }^{2}, \mathrm{LSC}^{2}$ and hybrid triangular-quadrangular grid) are used in this cross-scale application. We showed that the model is both accurate and efficient for this system. The sea-surface elevation, velocity, salinity and temperature and their vertical structures are all reasonably simulated by the model. The new model is very flexible in its horizontal and vertical grids, and thus can be easily extended into tributaries and sub-tributaries.

Through a series, of sensitivity tests, we have demonstrated the fundamental role the bathymetry plays in the estuarine and nearshore systems. Bathymetry smoothing commonly used in terrain-following coordinate models was shown to not only lead to consistency issues, but also fundamentally alter the system in terms of channel-shoal contrast, and volumetric and tracer fluxes.

The proper representation of the physical processes is a pre-requisite for water quality and biological studies in Chesapeake Bay and elsewhere. Therefore, the model presented in this paper represents a powerful tool that can be used to advance our understanding of the impact of both local and remote forcings on estuarine systems, which can ultimately lead to a holistic management strategy. 


\section{Acknowledgement}

This work is partially funded by EPA's Chesapeake Bay Program (\#CB-96326601). The authors thank Dr. Julie Herman for providing the USGS DEM, and anonymous reviewers for their comments and suggestions. Simulations presented in this paper were conducted using the following computational facilities: (1) Sciclone at the College of William and Mary which were provided with the assistance of the National Science Foundation, the Virginia Port Authority, and Virginia's Commonwealth Technology Research Fund; (2) the Extreme Science and Engineering Discovery Environment (XSEDE; Grant TG-OCE130032), which is supported by National Science Foundation grant number OCI-1053575; (3) NASA's Pleiades.

\section{Figure captions}

Figure 1: Observation assets used in this paper (including the appendix): NOAA tide gauges (red triangles), NOAA current measurements (green diamonds), CBP water quality casts (black circles; C: center; E: east; W: west; N: north; S: south), NASA's ocean surface temperature product G1SST (blue surface), and current measurements by cruises (dashed 
line).
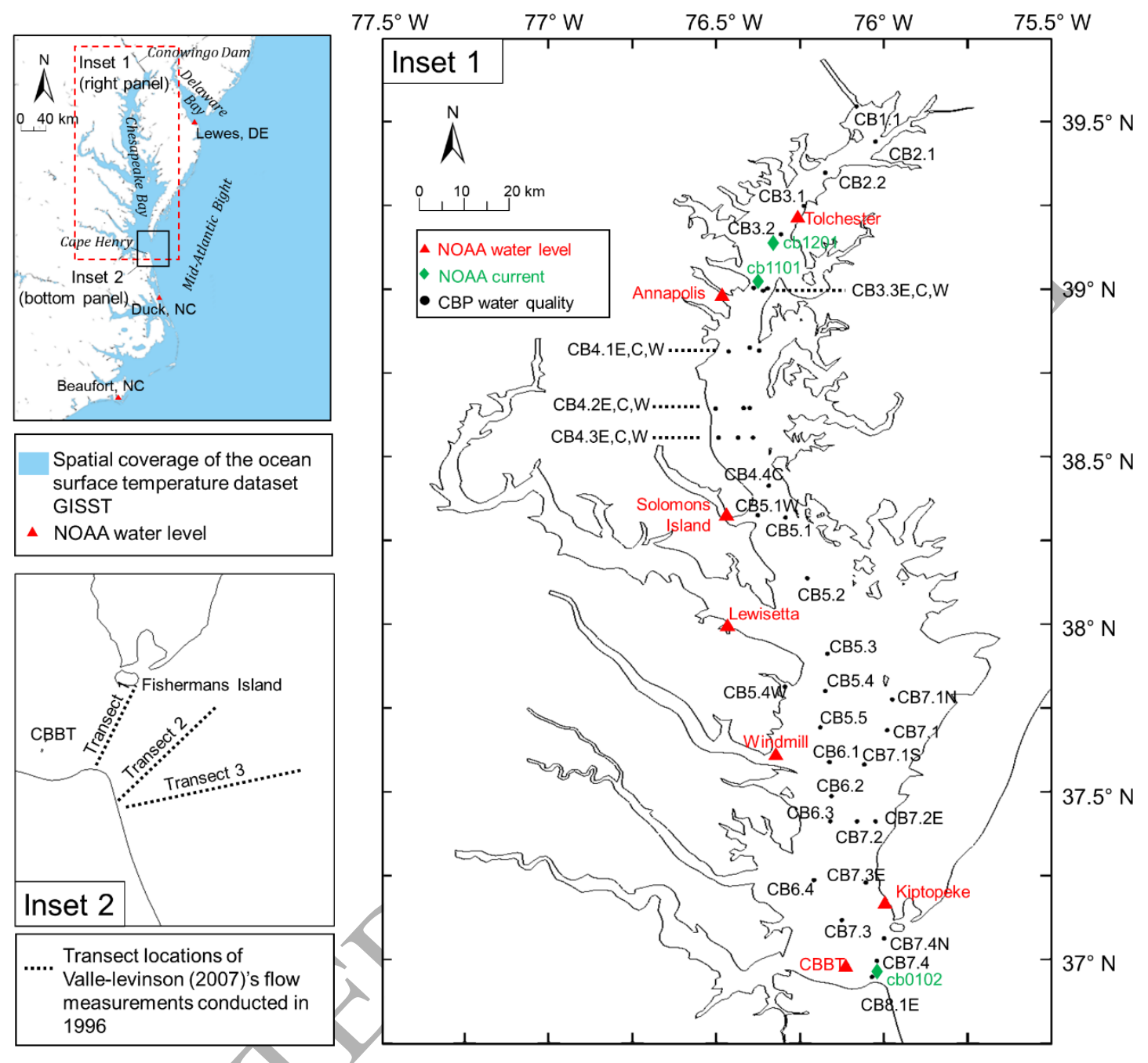

Figure 2: Digital Elevation Model (DEM) information including multiple zoom-ins (a-d) in different stretches of the main Bay showing the channel configuration and other bathymetric features. 


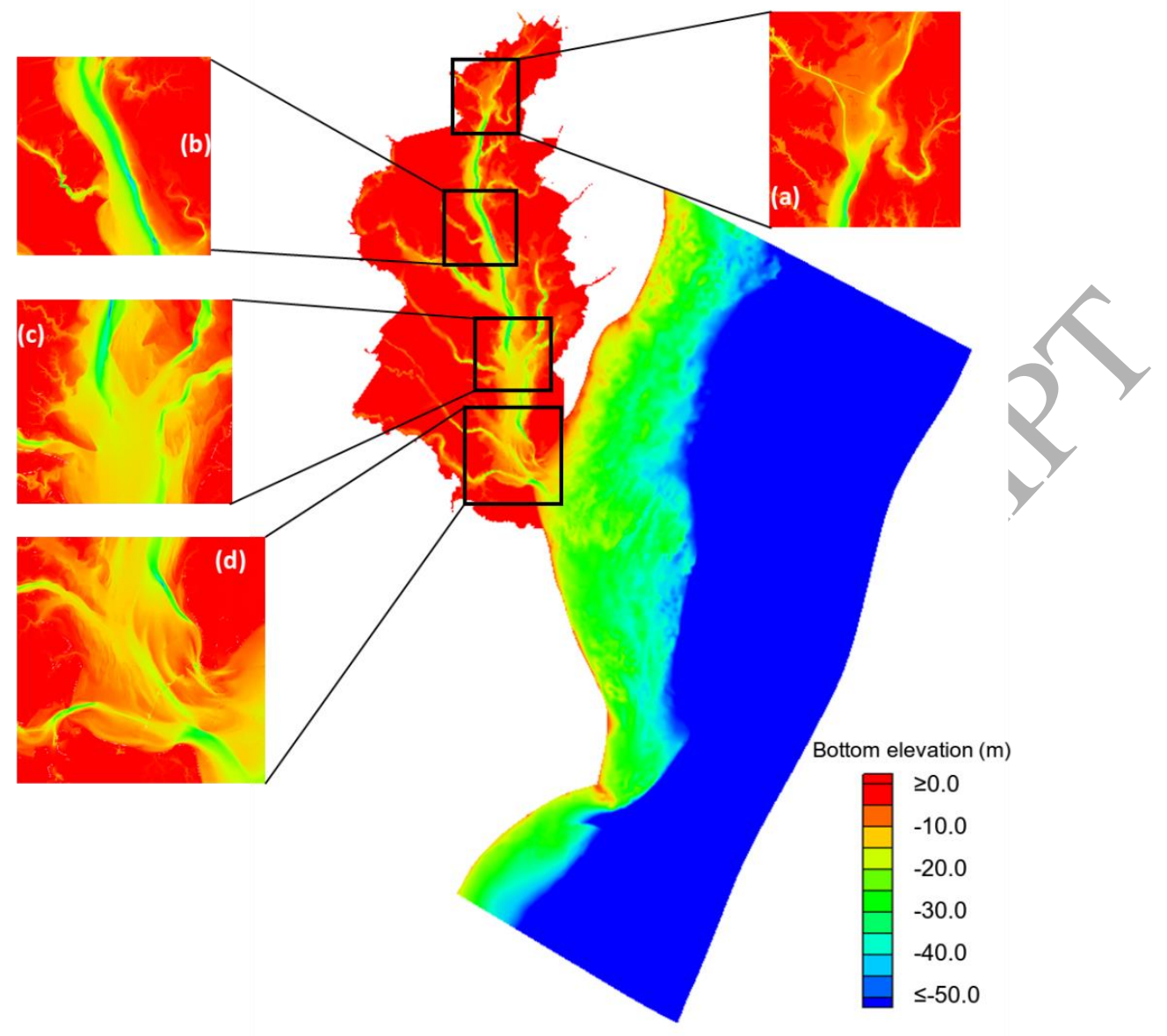

Figure 3: SMS 'map (a collection of arcs and polygons used to delineate the mesh boundary and important features) for (a) lower Bay; (b) upper Bay; (c) typical channel representation in SCHISM, with 2 nodes dispensed to represent each channel edge (one at the top and the other at the foot of the edge). In practice, more nodes may be inserted on the edge

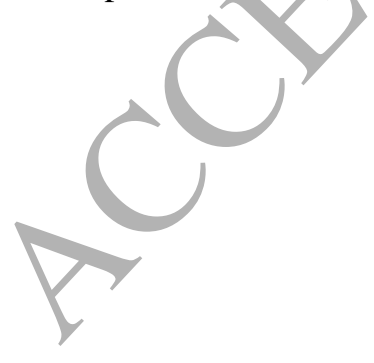




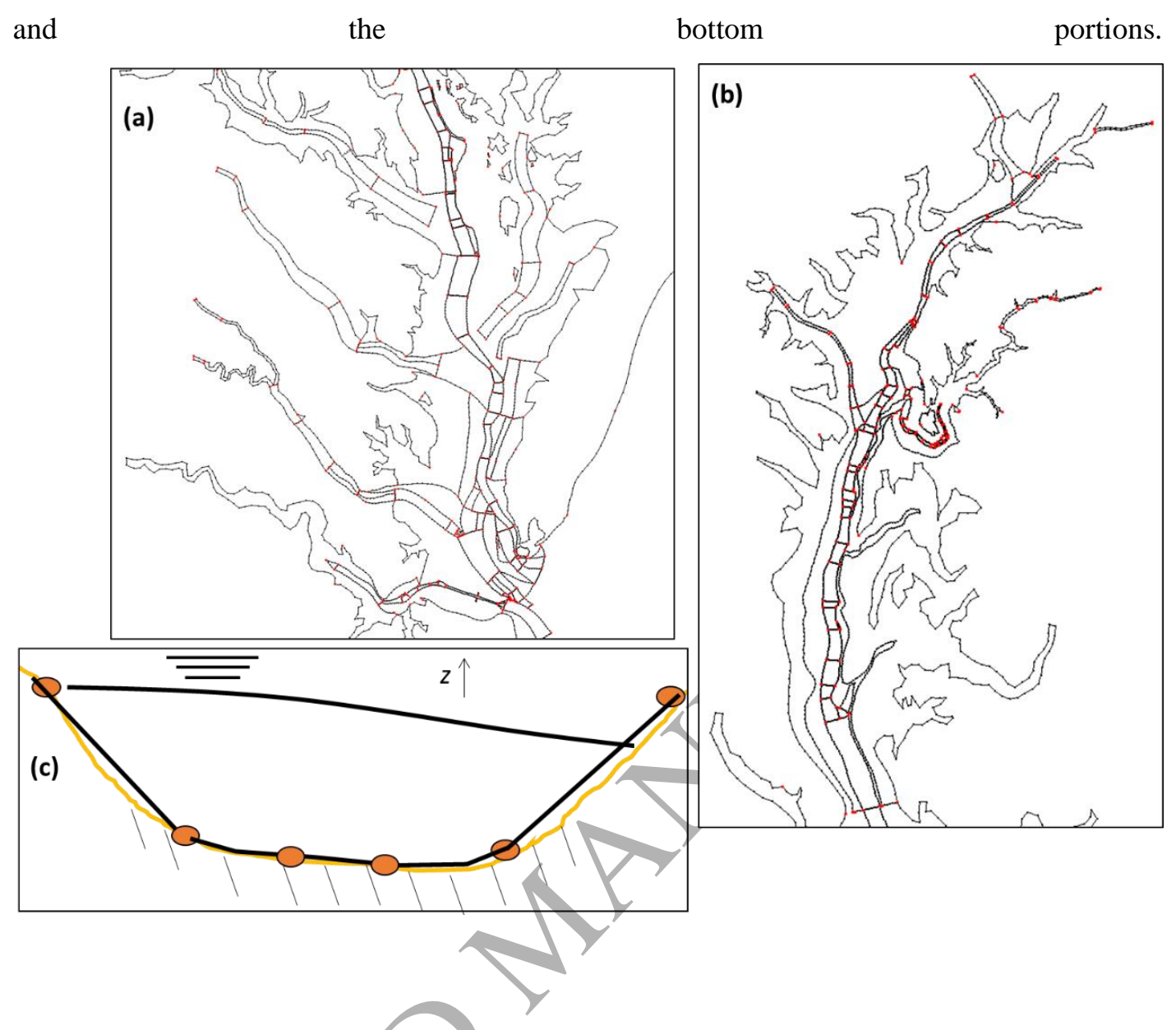

Figure 4: Horizontal grid with zooms. Average resolution in each region is also provided. 

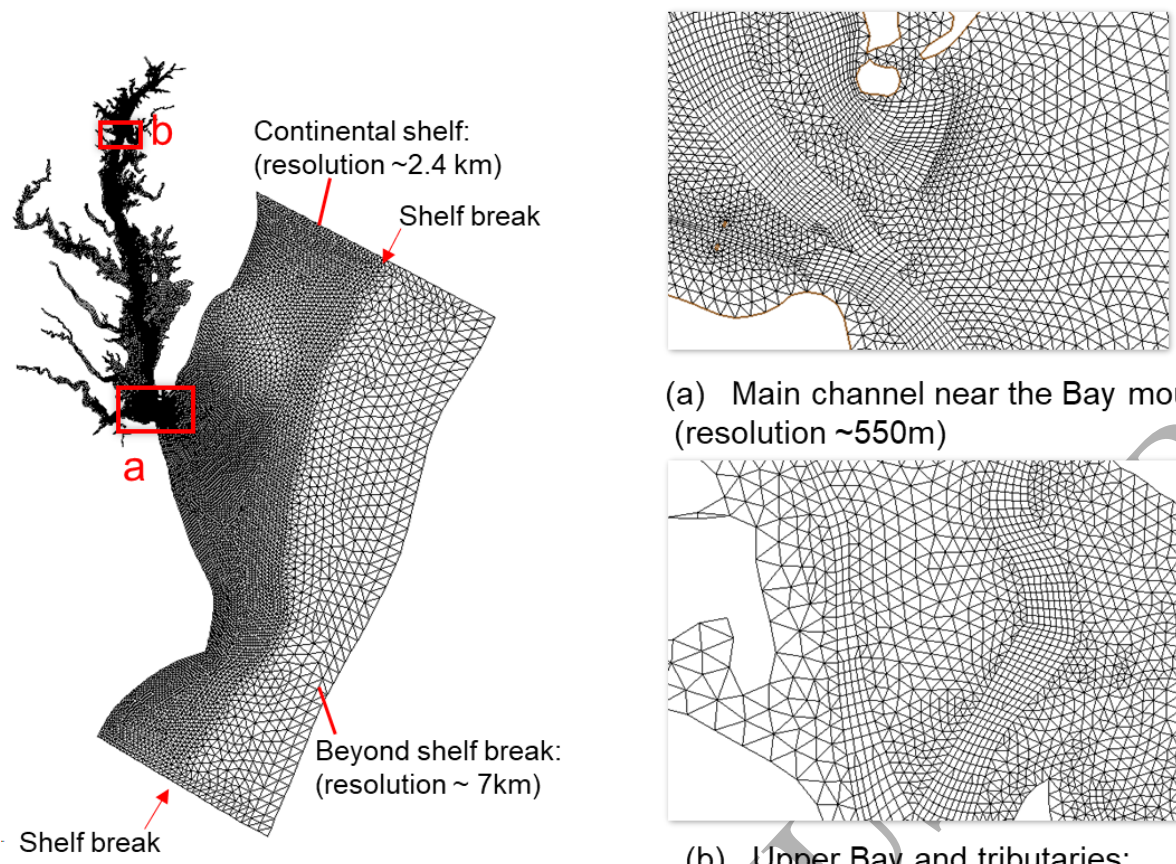

(a) Main channel near the Bay mouth (resolution $\sim 550 \mathrm{~m}$ )

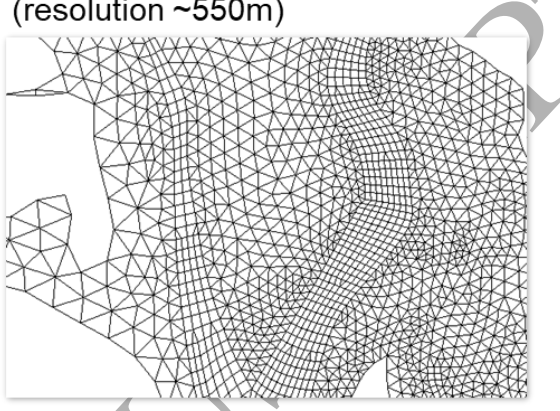

(b) Upper Bay and tributaries: (resolution $\sim 280 \mathrm{~m}$ )

Figure 5: Vertical grid. (a) Transect location from the upper Bay to the shelf break; (b) master grid (not the real model grid, but a reference for the configuration at each grid point) used for the Bay portion; (c) master grid used for the shelf portion; (d) the real model grid as seen along the transect shown in (a); (e) zoomed-in view on a stretch of the main channel inside the estuary. Note that the depth-varying vertical levels are nearly horizontal through most of the water column, which reduces pressure gradient error and diapycnal mixing; while shaved cells are applied near bottom, which ensure a smooth representation of the bottom and also reduces diapycnal mixing by cutting off the connectivity among bottom elements along a slope. 
(a) Transect location

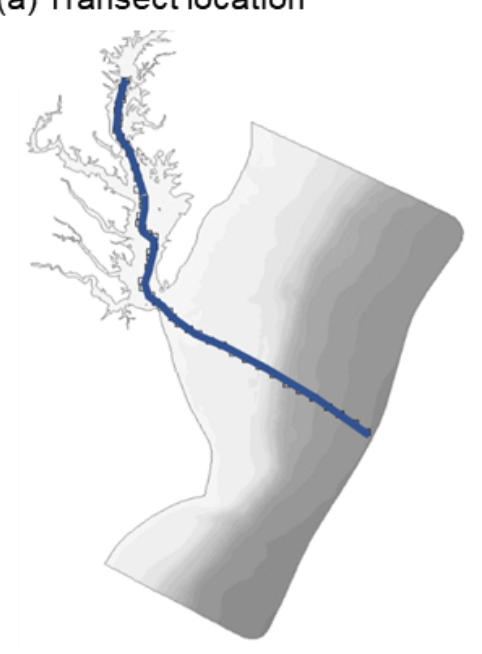

(b) Estuary master grid (resolving middepth; zoomed-in view on depth=0-30 m)

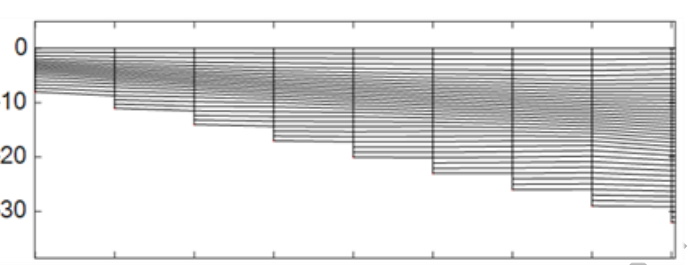

(c) Ocean ma zoomed-in vie

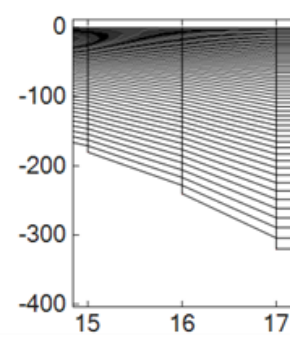

(d) Model grid: Es (e) Zoomed-in view of the model grid

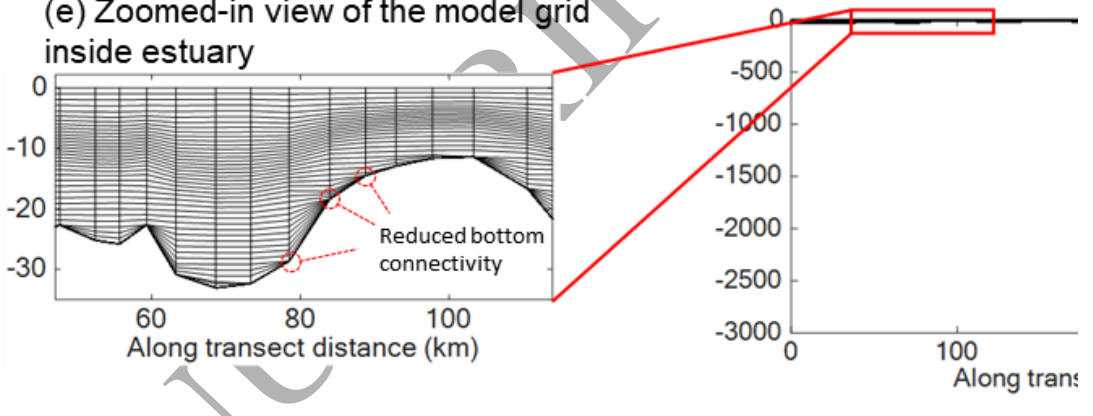

Figure 6: Total flow from all freshwater sources in years (a) 2011-2014; (b) 1996. 'USGS' is the sum of the gauged flow at 7 major tributaries; 'Watershed' is from CBP's watershed model. Note that watershed flows are not available to us for 1996. 

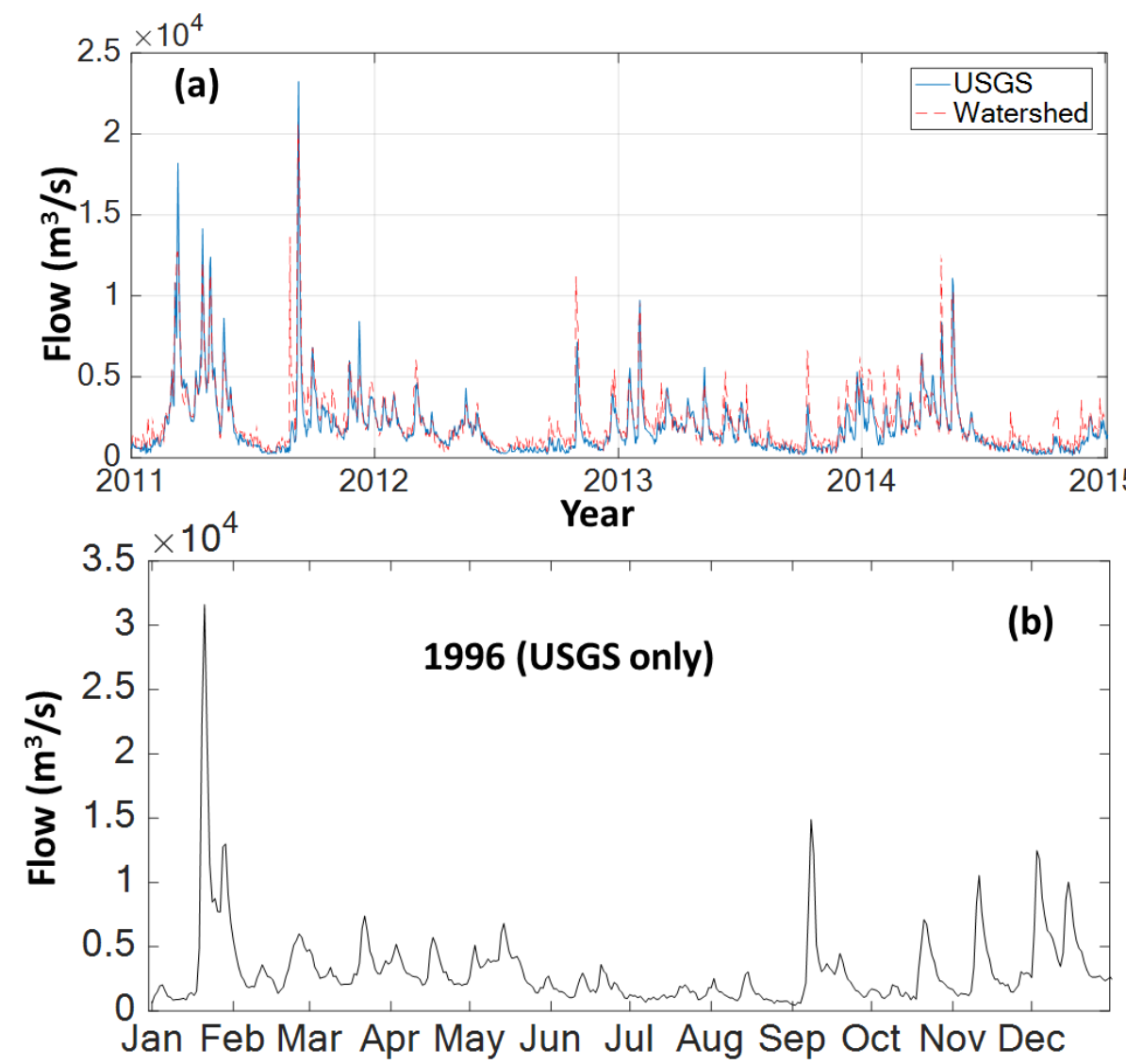

Month

Figure 7: Target diagram for salinity and temperature model skill.

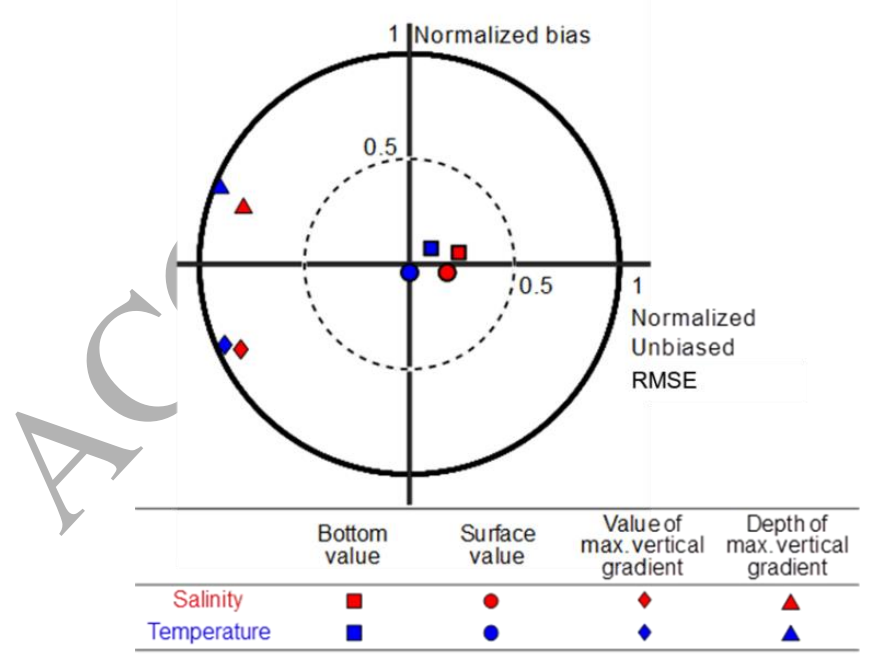


Figure 8: Time series of total (tidal plus sub-tidal frequency) elevation, showing a period including normal conditions and a storm condition at one station (CBBT) near the Bay mouth.

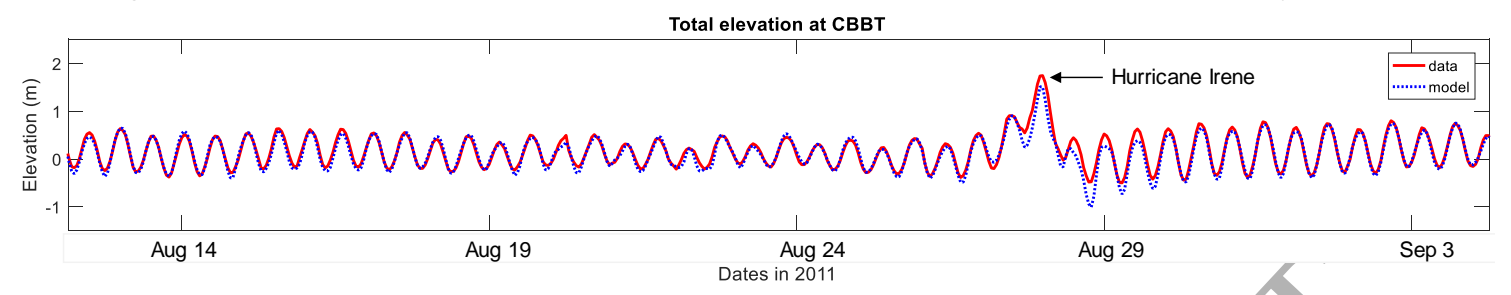

Figure 9: Tidal harmonics for 4 major constituents from 2011-2014. See Figure 1 for station
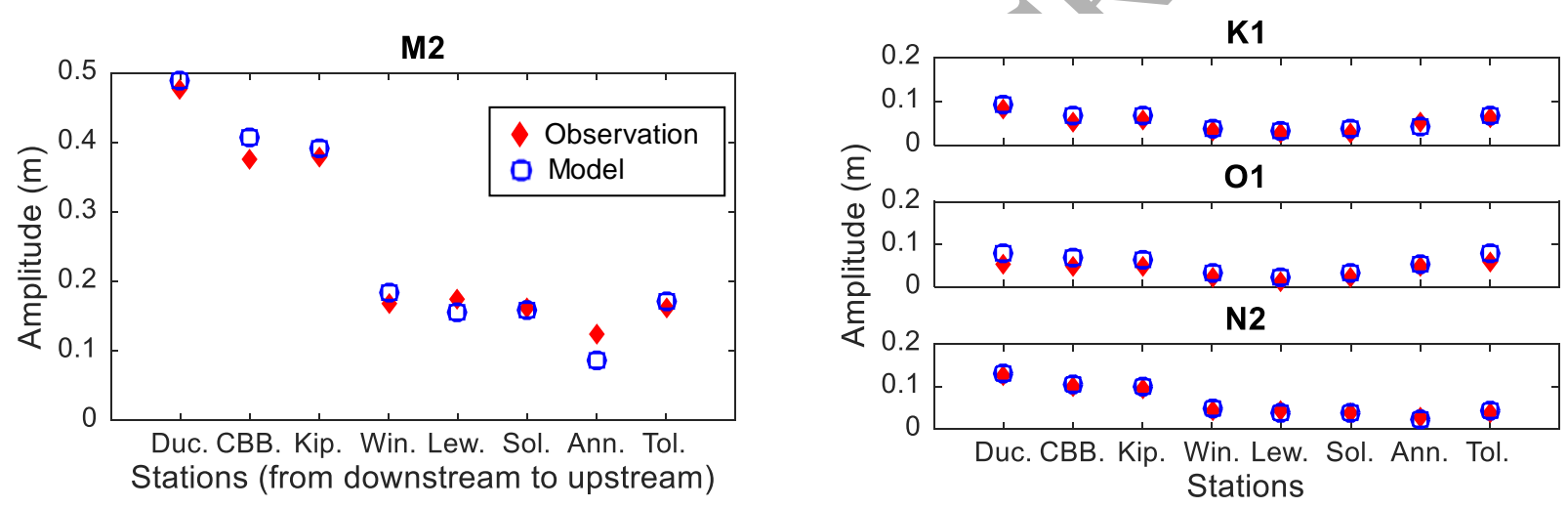

M2
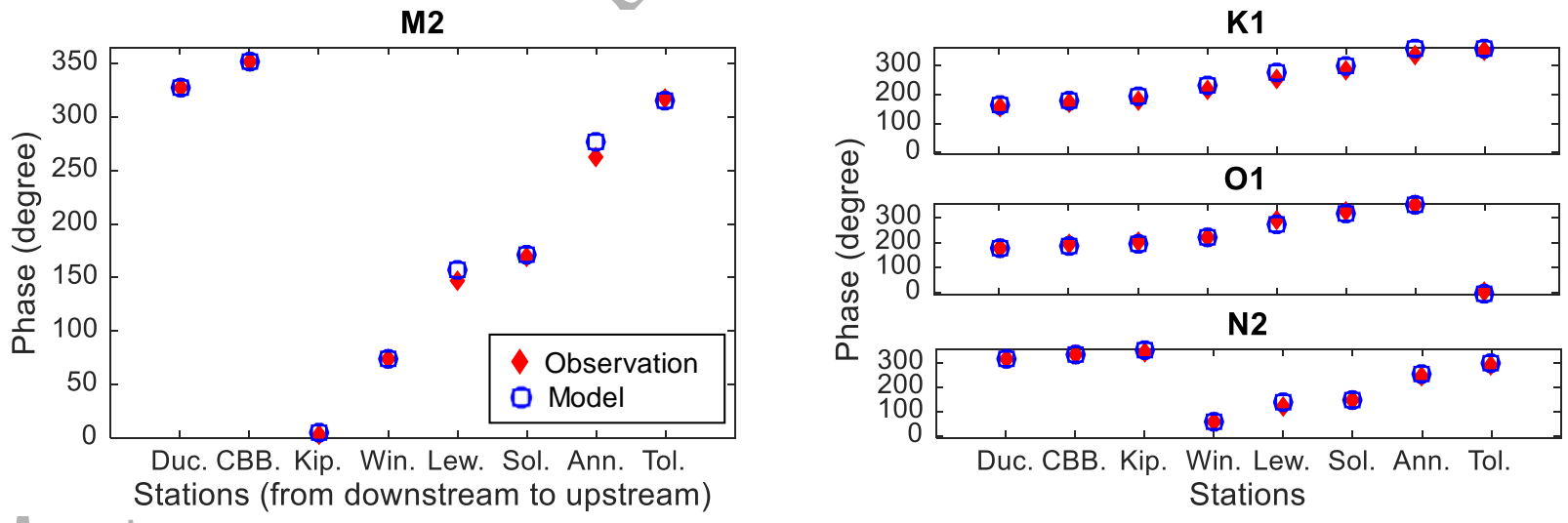

Figure 10: Sample comparisons of depth averaged along-channel velocity at three stations during three 1-month periods in 2012-2014. The averaged RMSE in 2012-2014 for all 


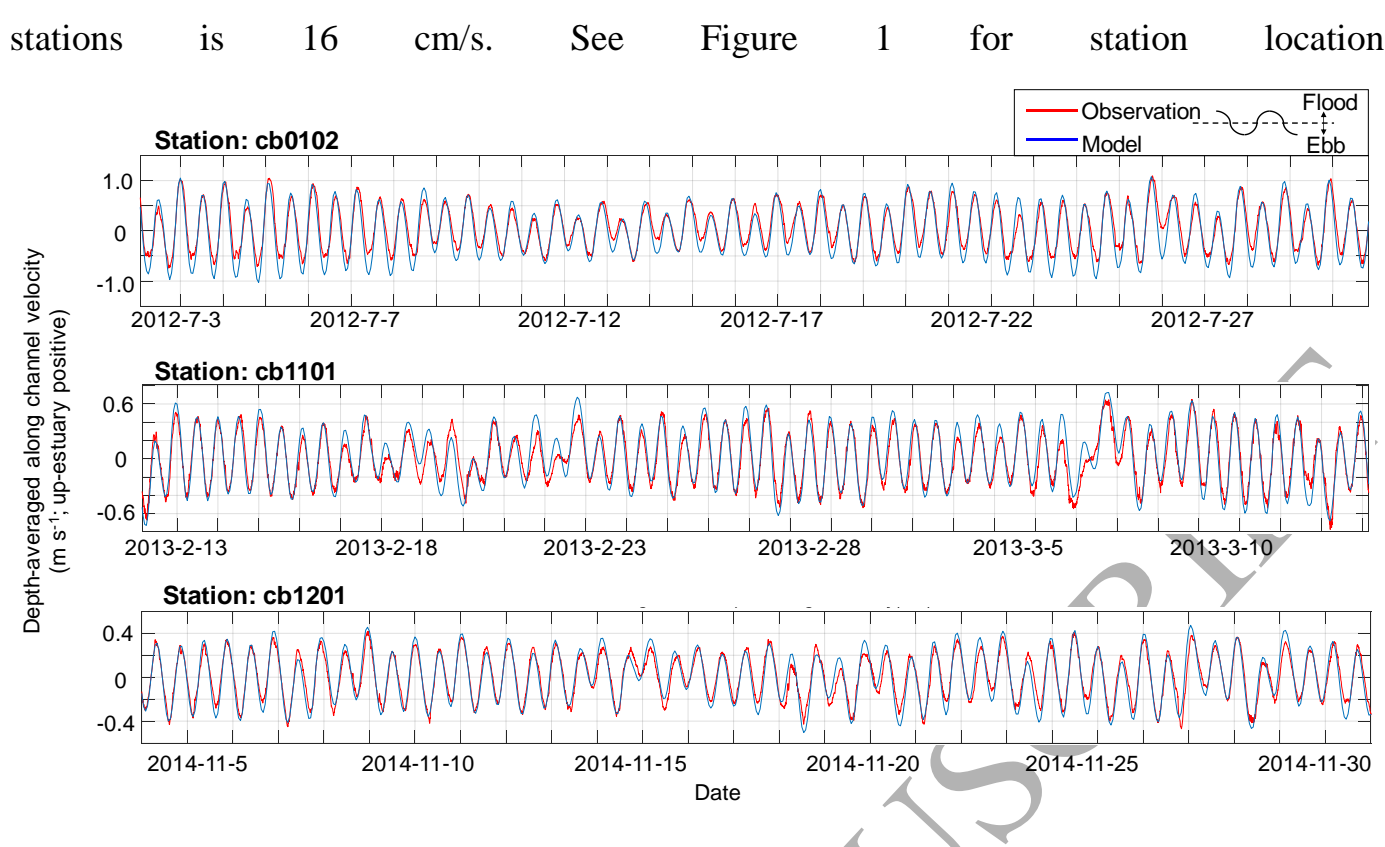

Figure 11: Averaged vertical profiles of along-channel velocity at the Bay mouth (cb0102) and upper Bay (cb1101 and cb1201). For each station, the left panel shows averaged velocity, with horizontal bars showing standard deviation; the right panel shows the corresponding RMSE's.
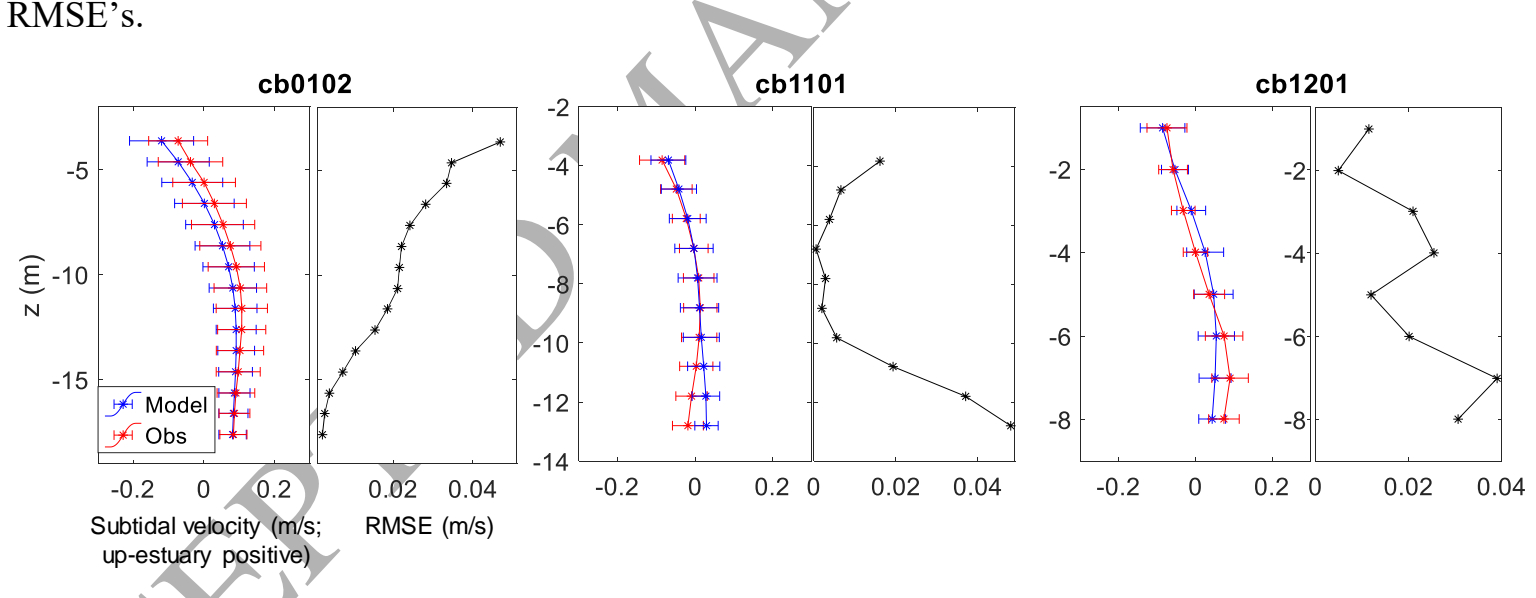

Figure 12: Averaged salinity transect for 2011-2014 along the main stem stations. It overlays the observations (CBP casts) on top of the model results; complete 'disappearance' of the 


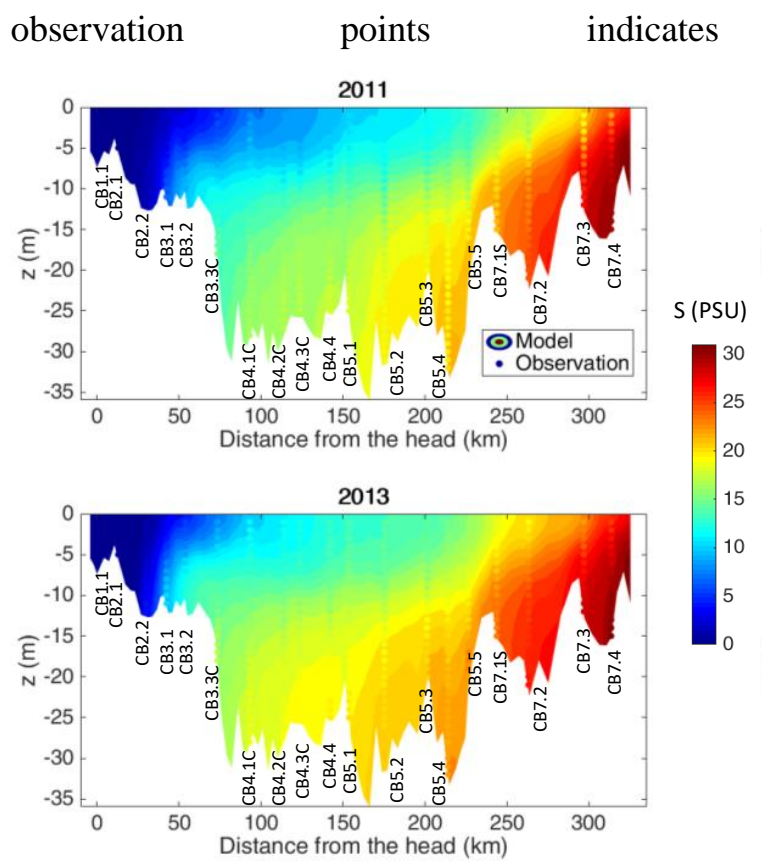

a

perfect

model.
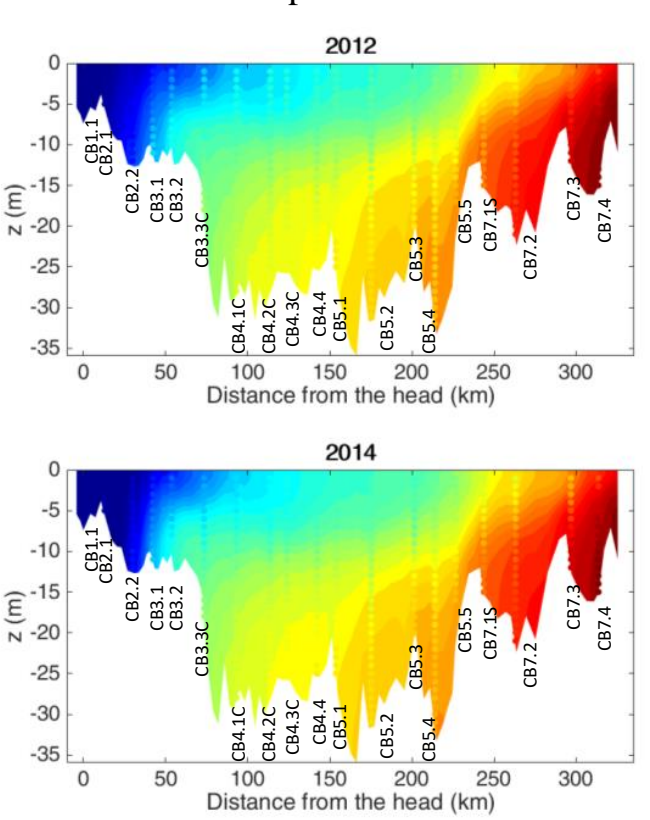

Figure 13: An example of DEM smoothing: (a) original DEM in Liberty Island in Sacramento-San Joaquin Delta, showing small-scale "moonscapes" of a few meters; (b) smoothed

DEM.

(a)

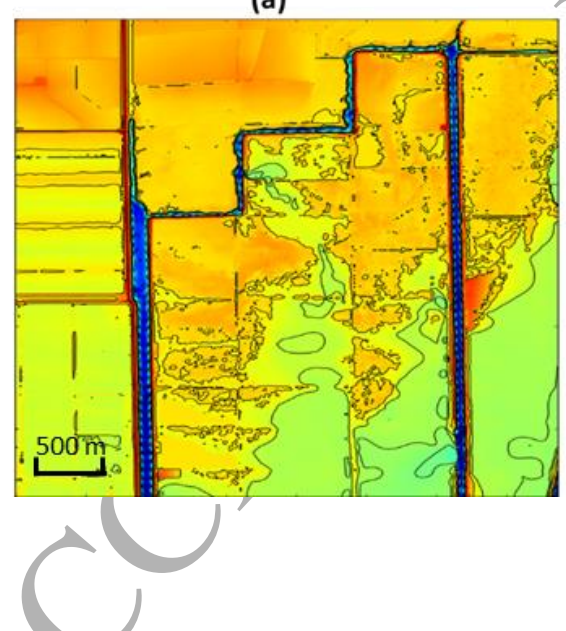

(b)

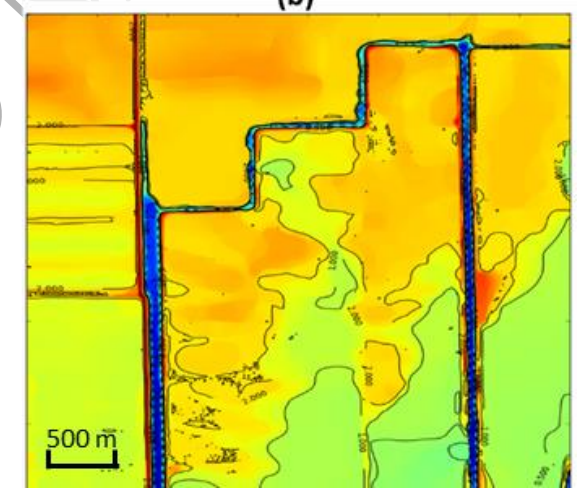

Figure 14: Effects of bathymetry smoothing. (a): The smoothed region (enclosed by the polygon with black lines) and the transect (red and blue lines) used in analysis; (b): time averaged vertical diffusivity along the blue portion of the transect with the original bathymetry; (c): same as (b) but with the smoothed bathymetry. The dashed line in (b) shows the bottom profile from the original highresolution DEM. The ellipses in (b) and (c) highlight the locations (steep slope and shoal) of the most obvious changes in mixing patterns. Effects of bathymetry smoothing on (d) salinity distribution and pycnocline position (white line at mid-depth); and (e) flow patterns (arrows represent cross-channel 
flow and colors represent along-channel velocity). All plots are time averaged from May to October in
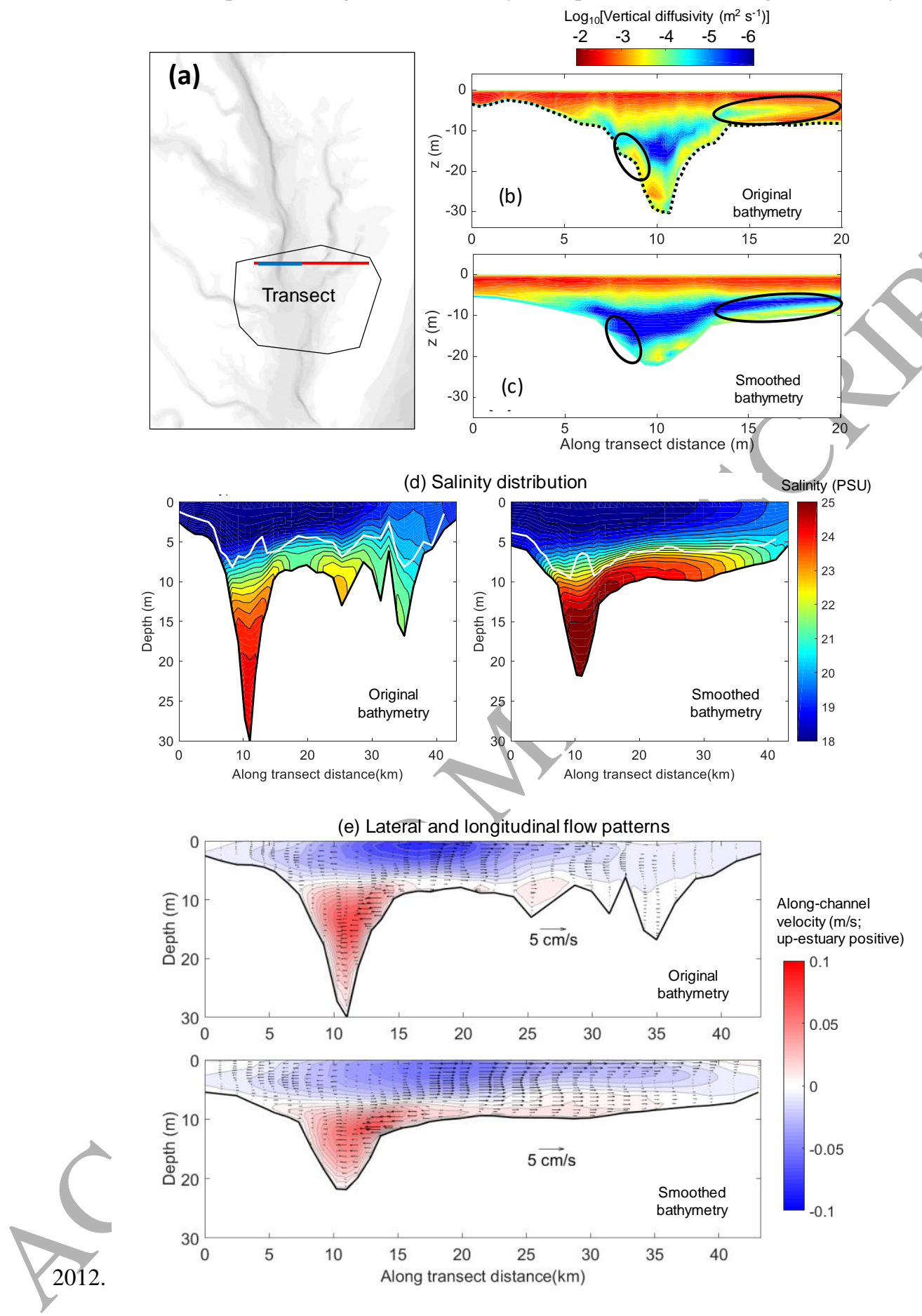
Figure 15: Typical comparisons of salinity profiles at two mid Bay stations (a) CB4.3C (channel) and (b) CB4.3E (shoal), with and without bathymetry smoothing.
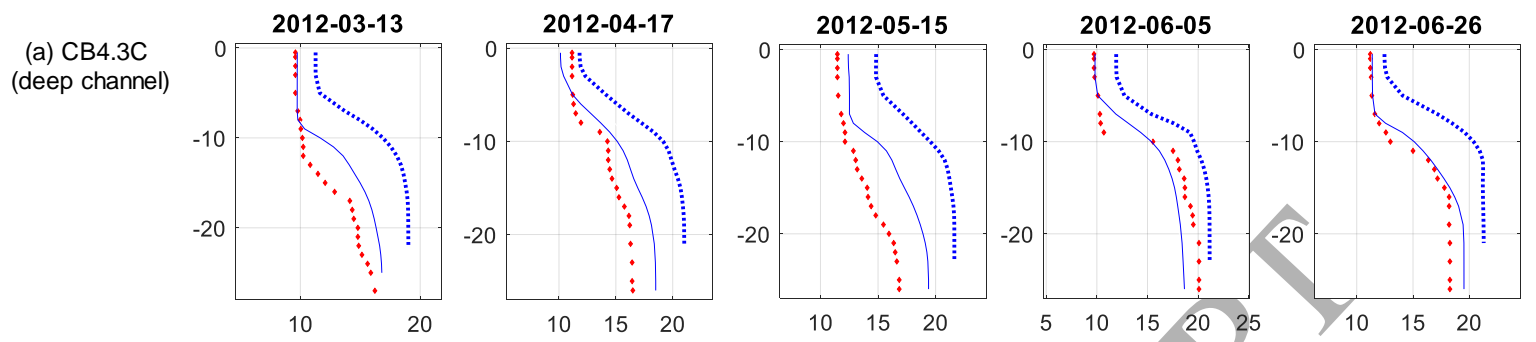

(b) CB4.3E
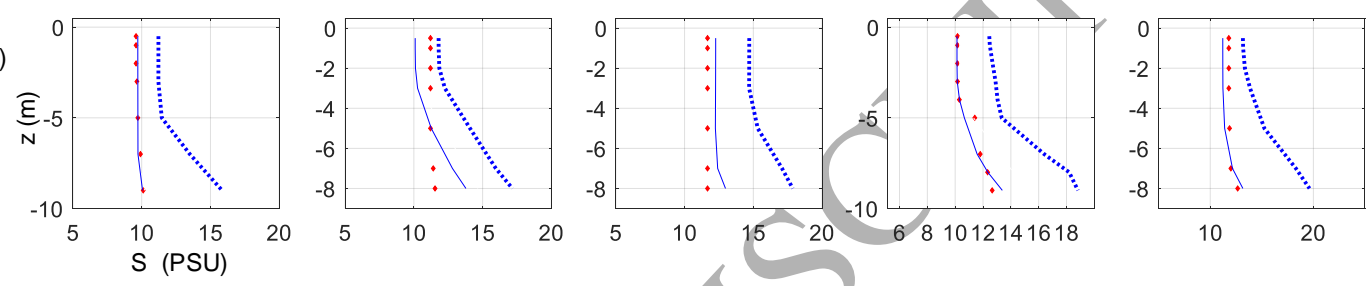

Observation

Baseline (original bathymetry)

Sensitivity test (smoothed bathymetry)

Figure 16: Simulated stratification (bottom salinity minus surface salinity, time-averaged in 2012): (left) original bathymetry; (right) smoothed bathymetry (with the same transport solver). Note that the zoomed-in views use a range of 0-1 PSU to mark the intrusion limit.
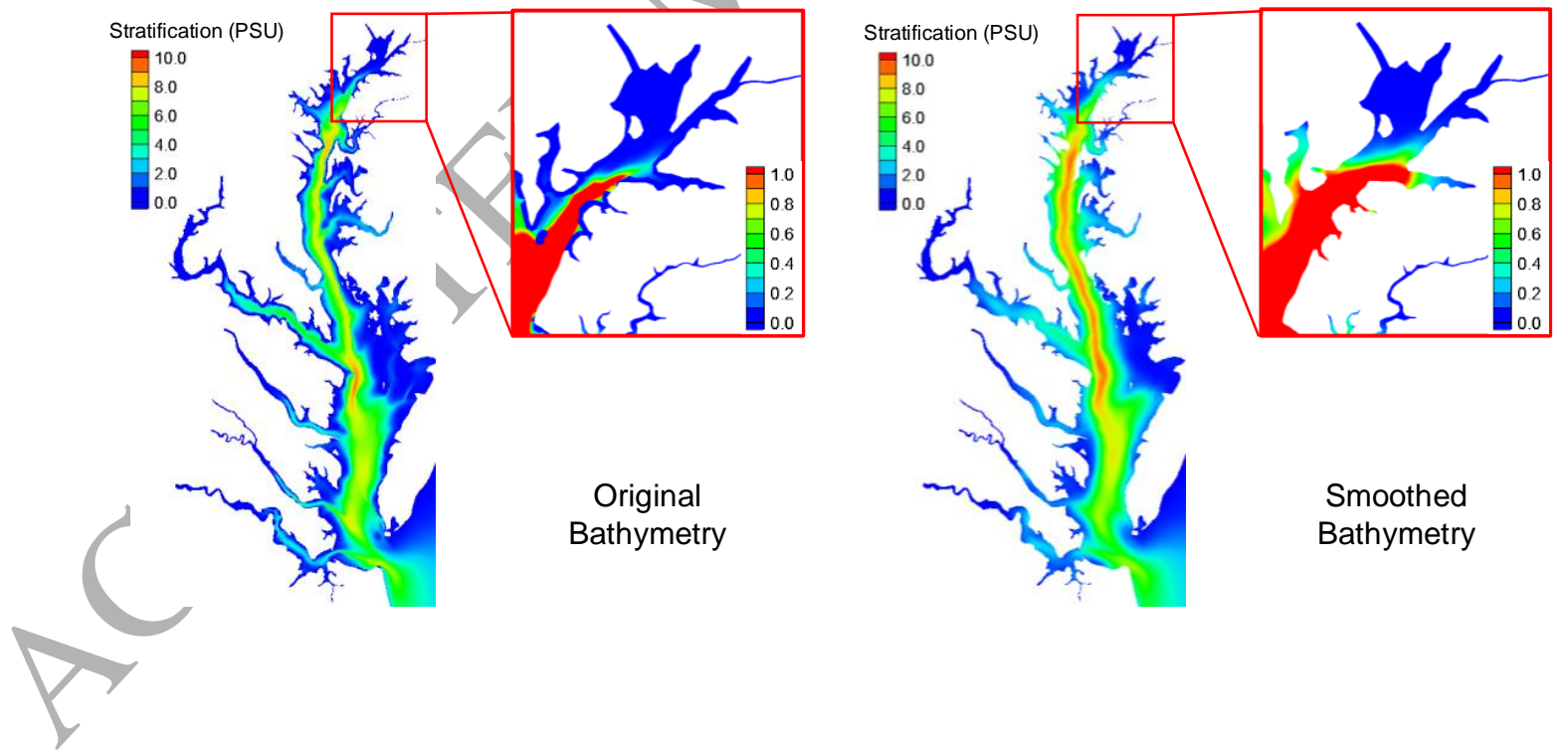

Figure 17: Salt flux decomposition $\left(F_{S} \approx Q_{f} s_{0}+F_{E}+F_{T}\right)$ at three cross-channel transects passing through CB7.4C (mouth), CB4.4 (mid-bay), and CB3.3C (upper bay) respectively (see their locations in Figure 1), with comparisons between original and 
smoothed

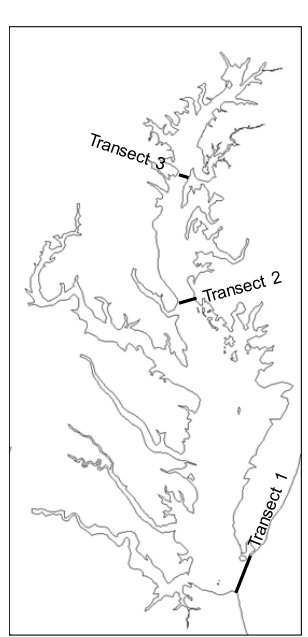

bathymetry.
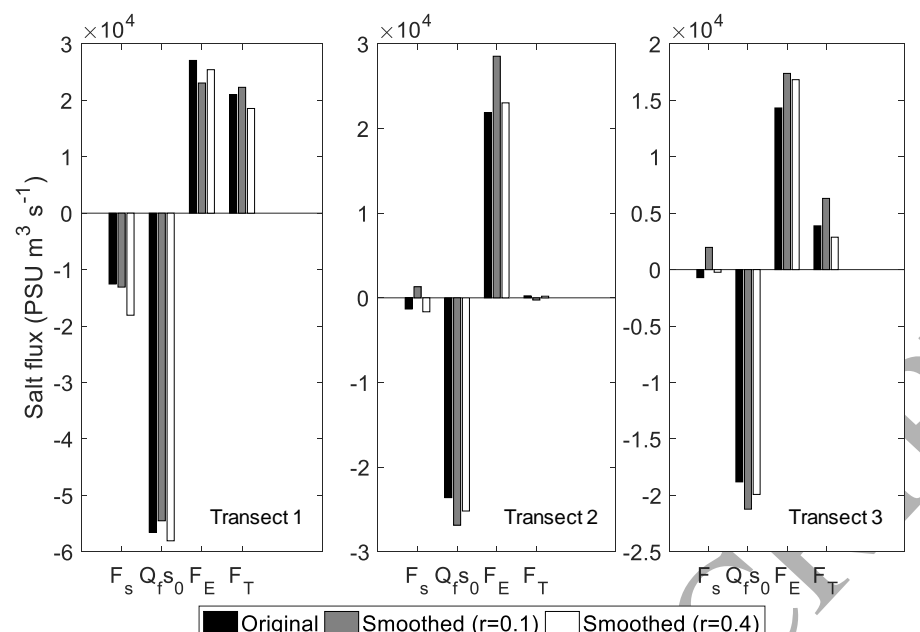

Figure 18: Difference in the simulated plume (defined as the water volume outside the Bay mouth enclosed by the 30-PSU iso-surface) between the original bathymetry and the smoothed bathymetry: (a) time series of plume volume and percentage change after smoothing; (b \& c) plume thickness in two representative months of (b) spring freshet and (c) low flow conditions in 2012. Note that the horizontal extents are different in (b) and (c). The plume areal extent is delineated by the 0 contour line.

(a) Time series of (left) plume volume and (right) percentage difference

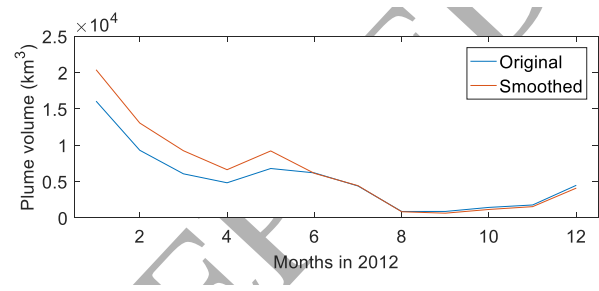

(b) Averaged plume thickness in March, 2012

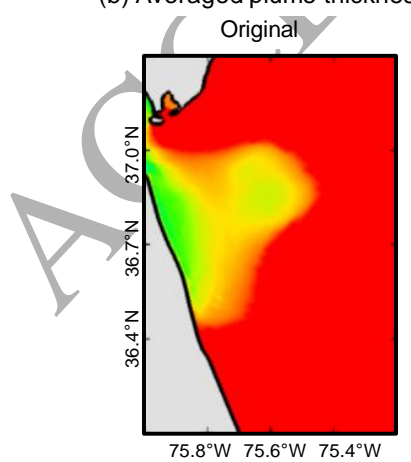

Smoothed

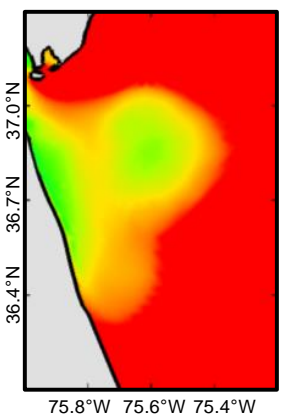

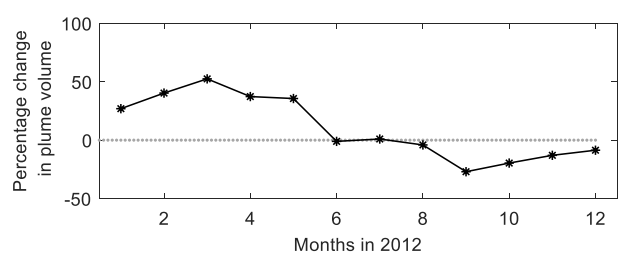

(c) Averaged plume thickness in September, 2012
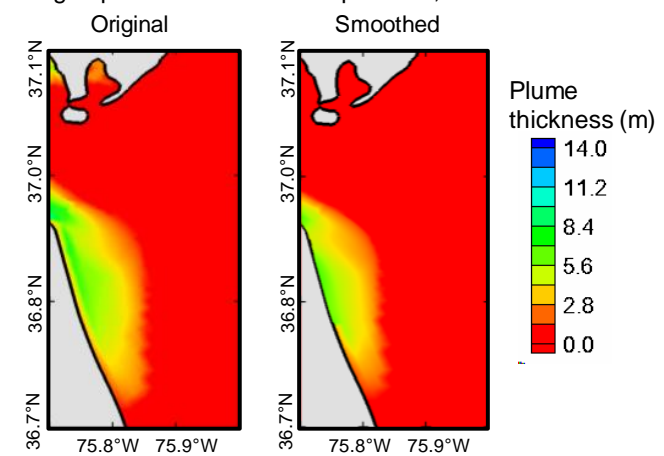
Figure A1: Typical salinity profile comparisons at main channel stations: (a) CB7.4, (b) CB7.1S, (c) CB4.4, (d) CB3.3C, (e) CB3.1; and shoal stations: (f) CB6.3, (g) CB4.3E, (h) CB3.3E.

Figure A1: Typical salinity profile comparisons at main channel stations: (a) CB7.4, (b) CB7.1S, (c) CB4.4, (d) CB3.3C, (e) CB3.1; and shoal stations: (f) CB6.3, (g) CB4.3E, (h) CB3.3E.

(c)
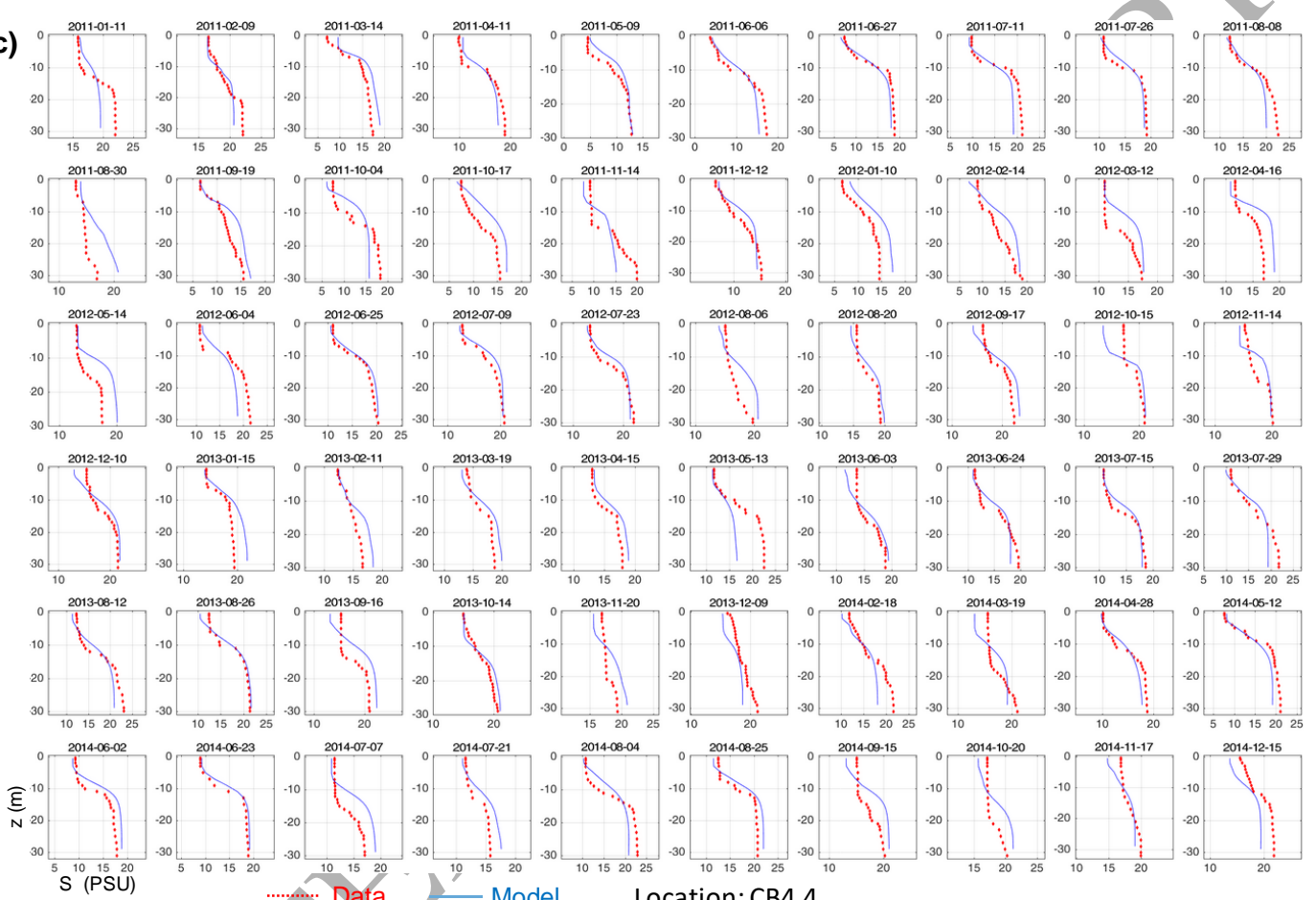

Data

Location: CB4.4 
Figure A2: (a) The simulated maximum plume extent on Nov. 8-9, 1996; (b) wind history at NDBC station CHLV2 during this period, where the red box indicates Nov. 8-9.
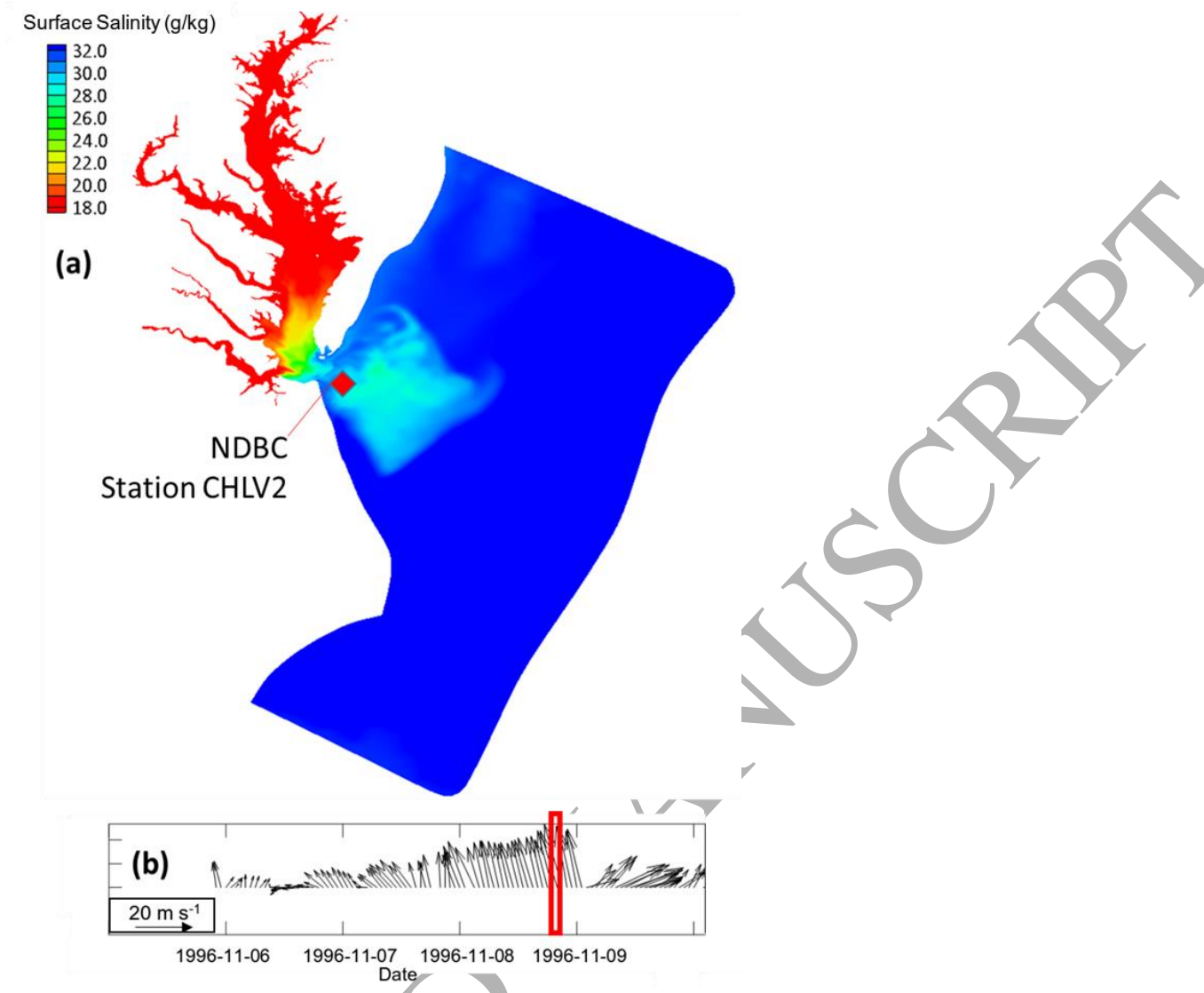

Figure A3: Sub-tidal frequency flows at each transect measured in (a) September and (b)

November 1996. Looking upstream, shaded areas indicate up-estuary flow perpendicular to

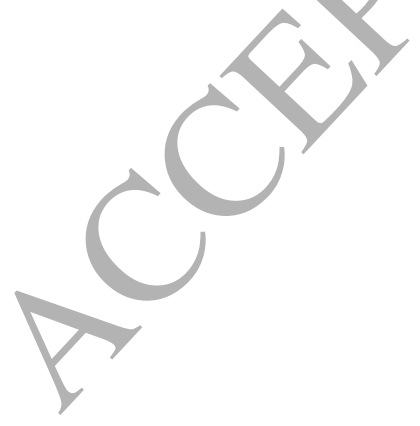


the

transect;

vectors

indicate

lateral

flow.

(a) Sep, 1996
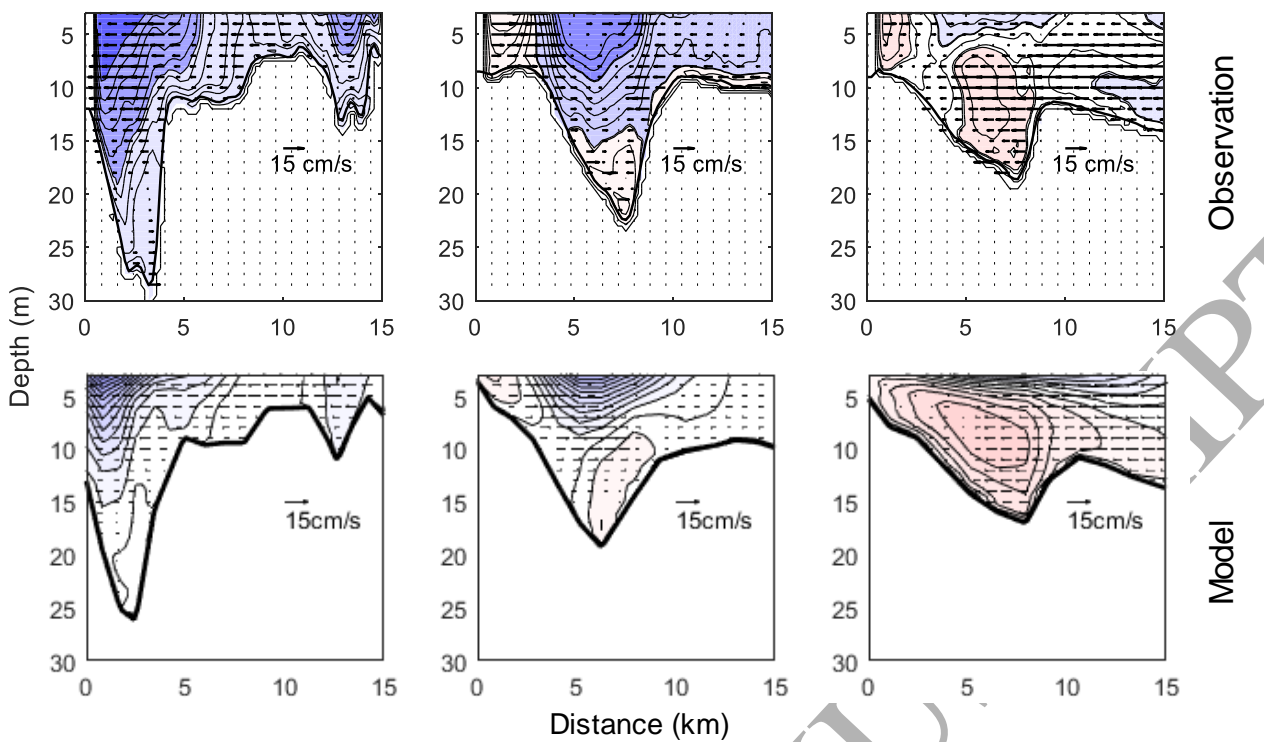

(b) Nov, 1996
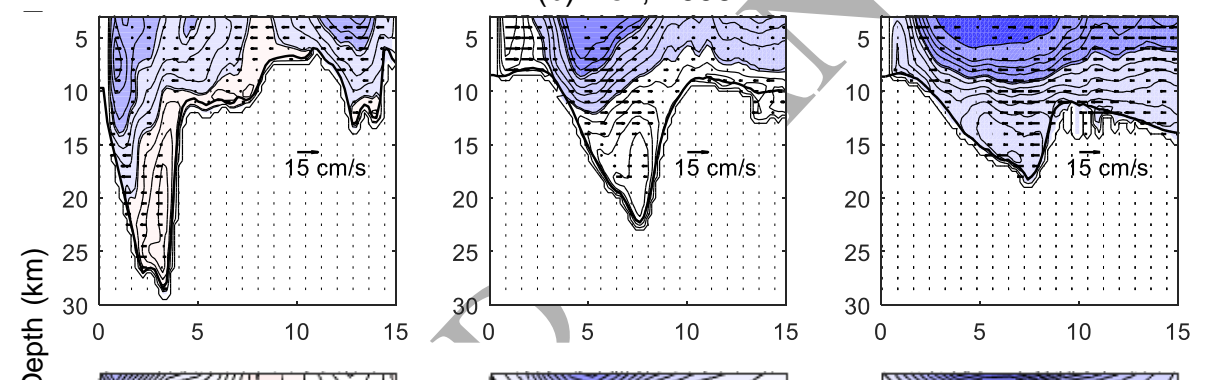

\section{을
을
20
0
0
0
0}
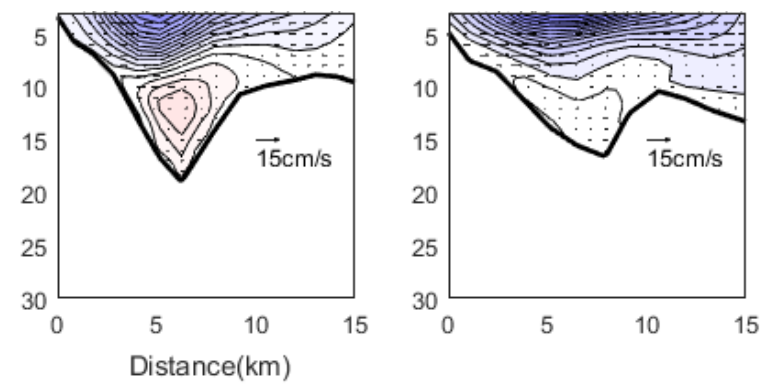

$\frac{\bar{\Phi}}{\overline{8}}$

$-100$

0

100

Cross-transect velocity ( $\mathrm{cm} / \mathrm{s}$; up-estuary positive) 
Figure A4: Comparison of monthly SST in 2012 from (a) G1SST; (b) SCHISM. Note that

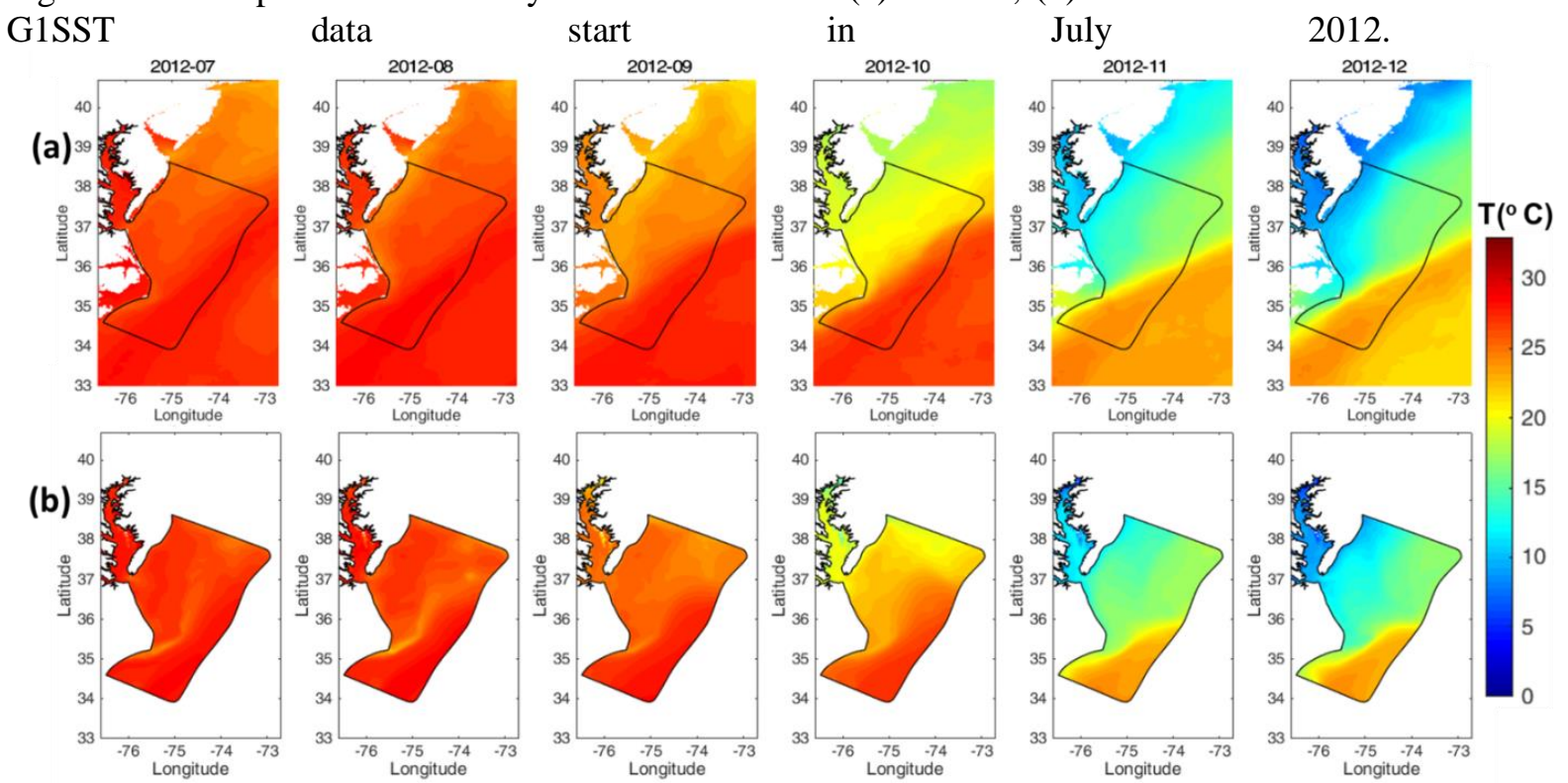

\section{References}

Andres, M. (2016), On the recent destabilization of the Gulf Stream path downstream of Cape Hatteras, Geophys. Res. Lett., 43, 9836-9842, doi:10.1002/2016GL069966.

Baptista, A.M. (1987) Solution of advection-dominated transport by Eulerian-Lgrangian Methods using the backwards method of characteristics. Ph.D. Dissertation, MIT, Cambridge.

Bever, A.J., Friedrichs, M.A.M., Friedrichs, C.T., Scully, M.E., Lanerolle, L.W.J., 2013. Combining observations and numerical model results to improve estimates of hypoxic volume within the Chesapeake Bay, USA. J. Geophys. Res. Ocean. 118, $4924-4944$.

Boesch, D.F., Brinsfield, R.B., Magnien, R.E., 2001. Chesapeake Bay eutrophication: scientific understanding, ecosystem restoration, and challenges for agriculture. J. Environ. Qual. 30, 303-320.

Brown, C.A. and Ozretich, R.J., 2009. Coupling between the coastal ocean and Yaquina Bay, Oregon: Importance of oceanic inputs relative to other nitrogen sources. Estuaries and Coasts, 32(2), pp.219-237.

Casulli, V. and Cattani, E. (1994) Stability, accuracy and efficiency of a semi-implicit method for 3D shallow water flow. Computers \& Mathematics with Applications, 27, pp. 99-112.

Cerco, C., Noel, M., 2004. The 2002 Chesapeake Bay Eutrophication Model. 
Cerco, C.F., Noel, M.R., Wang, P., 2013. The shallow-water component of the Chesapeake Bay Environmental Model Package. JAWRA J. Am. Water Resour. Assoc. 49, 10911102.

Chao, Y., Z. Li, J. D. Farrara, and P. Huang: Blended sea surface temperatures from multiple satellites and in-situ observations for coastal oceans. Journal of Atmospheric and Oceanic Technology, 26 (7), 1435-1446, 10.1175/2009JTECHO592.1, 2009.

Chen, K., R. He, B. S. Powell, G. G. Gawarkiewicz, A. M. Moore, and H. G. Arango (2014), Data assimilative modeling investigation of Gulf Stream Warm Core Ring interaction with continental shelf and slope circulation, J. Geophys. Res. Oceans, 119, 59685991, doi:10.1002/2014JC009898.

Du, J., and Shen, J., 2015. Decoupling the influence of biological and physical processes on the dissolved oxygen in the Chesapeake Bay. J. Geophys. Res. Ocean. 120, 78-93.

Du, J. and Shen, J., 2016. Water residence time in Chesapeake Bay for 1980-2012. Journal of Marine Systems, 164, pp.101-111.

Dukhovskoy, D.S., Morey, S.L., O'Brien, J.J., Martin, P.J., and Cooper, C. (2009) Application of a vanishing quasi-sigma vertical coordinate for simulation of highspeed deep currents over the Sigsbee Escarpment in the Gulf of Mexico, Ocean Mod., $28,250-265$.

Ezer, T. (2013), Sea level rise, spatially uneven and temporally unsteady: Why the U.S. East Coast, the global tide gauge record, and the global altimeter data show different trends, Geophys. Res. Lett., 40, 5439-5444, doi:10.1002/2013GL057952.

Feng, Y., Friedrichs, M.A.M., Wilkin, J., Tian, H., Yang, Q., Hofmann, E. E., Wiggert, J. D. and Hood, R. R. 2015. Chesapeake Bay nitrogen fluxes derived from a land-estuarine ocean biogeochemical modeling system: Model description, evaluation, and nitrogen budgets, J. Geophys. Res. Biogeosci., 120, 1666-1695, doi:10.1002/2015JG002931.

Fong, D.A. and W.R. Geyer 2002. The alongshore transport of fresh water in a surfacetrapped river plume. J. Phys. Oceanogr. 32:957-972

Gong, W. and Shen, J, 2011. The response of salt intrusion to changes in river discharge and tidal mixing during the dry season in the Modaomen Estuary, China. Continental Shelf Research, 31(7), pp.769-788.

Goodrich, D.M., Boicourt, W.C., Hamilton, P., Pritchard, D.W., 1987. Wind-Induced Destratification in Chesapeake Bay. J. Phys. Oceanogr. 17, 2232-2240.

Hagy, J.D., Boynton, W.R., Keefe, C.W., Wood, K. V., 2004. Hypoxia in Chesapeake Bay, 1950 2001: Long-term change in relation to nutrient loading and river flow. Estuaries 27, 634-658.

Haney, R.L. (1991) On the pressure gradient force over steep topography in sigma coordinate ocean models. J. Phys. Oceano., 21, pp. 610-618.

Hannah, C.G. , Wright, D.G. , 1995. Depth dependent analytical and numerical solutions for wind-driven flow in the coastal ocean. In: Lynch, D.R., Davies, A.M. (Eds.). In: Quantitative Skill Assessment for Coastal Ocean Models, 47. A.G.U., pp. 125-152.

Hofmann, E., Druon, J.-N., Fennel, K., Friedrichs, M., Haidvogel, D., Lee, C., Mannino, A., McClain, C., Najjar, R., O’Reilly, J., Pollard, D., Previdi, M., Seitzinger, S., Siewert, 
J., Signorini, S., Wilkin, J., Team, Usec., 2008. Eastern US continental shelf carbon budget: integrated models, data assimilation, and analysis. Oceanography 21, 86-104.

Holleman, R., Fringer, O. and Stacey, M. (2013), Numerical diffusion for flow-aligned unstructured grids with application to estuarine modeling. Int. J. Numer. Meth. Fluids, 72: 1117-1145. doi:10.1002/fld.3774.

Hong, B. and Shen, J., 2012. Responses of estuarine salinity and transport processes to potential future sea-level rise in the Chesapeake Bay. Estuarine, Coastal and Shelf Science, 104, 33-45.

Hu, H. and Wang, J., 2010. Modeling effects of tidal and wave mixing on circulation and thermohaline structures in the Bering Sea: Process studies. Journal of Geophysical Research: Oceans, 115(C1).

Irby, I.D., Friedrichs, M.A.M., Friedrichs, C.T., Bever, A.J., Hood, R.R., Lanerolle, L.W.J., Li, M., Linker, L., Scully, M.E., Sellner, K., Shen, J., Testa, J., Wang, H., Wang, P., Xia, M., 2016. Challenges associated with modeling low-oxygen waters in Chesapeake Bay: a multiple model comparison. Biogeosciences. 13 (7), 2011-2028.

Jiang, L. and Xia, M., 2016. Dynamics of the Chesapeake Bay outflow plume: Realistic plume simulation and its seasonal and interannual variability. Journal of Geophysical Research: Oceans, 121(2), pp.1424-1445.

Jolliff, J.K., Kindle, J.C., Shulman, I., Penta, B., Friedrichs, M.A.M., Helber, R., Arnone, R.A., 2009. Summary diagrams for coupled hydrodynamic-ecosystem model skill assessment. J. Mar. Syst. 76, 64-82.

Kemp, W., Boynton, W., Adolf, J., Boesch, D., Boicourt, W., Brush, G., Cornwell, J., Fisher, T., Glibert, P., Hagy, J., Harding, L., Houde, E., Kimmel, D., Miller, W., Newell, R., Roman, M., Smith, E., Stevenson, J., 2005. Eutrophication of Chesapeake Bay: historical trends and ecological interactions. Mar. Ecol. Prog. Ser. 303, 1-29.

Khangaonkar, T., Sackmann, B., Long, W., Mohamedali, T. and Roberts, M., 2012. Simulation of annual biogeochemical cycles of nutrient balance, phytoplankton bloom (s), and DO in Puget Sound using an unstructured grid model. Ocean Dynamics, 62(9), pp.1353-1379.

Kwizak, M. and Robert, A. 1971. Impicit integration of a grid point model, Mon. Weather Rev. 99: 32-36.

Lanerolle, L., Patchen, R., Aikman, F., 2011. NOAA technical report NOS CS 29: the second generation Chesapeake Bay operational forecast system model development and skill assessment.

Lerczak, J.A., Geyer, W.R. and Chant, R.J., 2006. Mechanisms driving the time-dependent salt flux in a partially stratified estuary. Journal of Physical Oceanography, 36(12), pp.2296-2311.

Li, M., Zhong, L. and Boicourt, W.C., 2005. Simulations of Chesapeake Bay estuary: Sensitivity to turbulence mixing parameterizations and comparison with observations. Journal of Geophysical Research: Oceans, 110 (C12).

Mallidi R and Sethian J.A. (1996) Image Processing: Flows under Min/Max Curvature and Mean Curvature, Graphical Models and Image Processing (58), p127-141. 
Möller, O.O., Castaing, P., Salomon, J.C. and Lazure, P., 2001. The influence of local and non-local forcing effects on the subtidal circulation of Patos Lagoon. Estuaries, 24(2), pp.297-311.

Murphy, R.R., Kemp, W.M., Ball, W.P., 2011. Long-term trends in Chesapeake Bay seasonal hypoxia, stratification, and nutrient loading. Estuaries and Coasts. 34, 1293-1309.

Najjar, R.G., Pyke, C.R., Beth, M., Breitburg, D., Hershner, C., Kemp, M., Howarth, R., Mulholland, M.R., Paolisso, M., Secor, D., Sellner, K., Wardrop, D., Wood, R., 2010. Potential climate-change impacts on the Chesapeake Bay. Estuar. Coast. Shelf Sci. 86, $1-20$.

Officer, C., Biggs, R., Taft, J., Cronin, L., 1984. Chesapeake Bay anoxia: origin, development, and significance. Science (80-. ). 223, 22-27.

Pein, J.U., Stanev, E.V., and Zhang. Y. (2014) The tidal asymmetries and residual flows in Ems Estuary, Ocean Dynamics, 64, 1719-41.

Richtmyer, R.D., 1957. Difference method for initial-value problems, $1^{\text {st }}$ edition, New York, Wiley, 238pp.

Sanford, L.P., Suttles, S.E. \& Halka, J.P. Estuaries (2001) 24: 655. doi:10.2307/1352874.

Schubel, J.R. and Pritchard, D.W., 1986. Responses of upper Chesapeake Bay to variations in discharge of the Susquehanna River. Estuaries, 9(4), pp.236-249.

Scully, M.E., Friedrichs, C., Brubaker, J., 2005. Control of estuarine stratification and mixing by wind-induced straining of the estuarine density field. Estuaries 28, 321-326.

Shenk, G.W. and Linker, L.C., 2013. Development and application of the 2010 Chesapeake Bay watershed total maximum daily load model. JAWRA Journal of the American Water Resources Association, 49(5), pp.1042-1056.

Stanev, E.V., Grashorn, S. and Zhang, Y.J. (2017) Cascading ocean basins: Numerical simulations of the circulation and inter-basin exchange in the Azov-Black-MarmaraMediterranean Seas system, Ocean Dyn., DOI 10.1007/s10236-017-1071-2.

Sutherland, D.A., MacCready, P., Banas, N.S. and Smedstad, L.F., 2011. A model study of the Salish Sea estuarine circulation. Journal of Physical Oceanography, 41(6), pp.1125-1143.

Testa, J.M., Li, Y., Lee, Y.J., Li, M., Brady, D.C., Di Toro, D.M., Kemp, W.M. and Fitzpatrick, J.J., 2014. Quantifying the effects of nutrient loading on dissolved O2 cycling and hypoxia in Chesapeake Bay using a coupled hydrodynamicbiogeochemical model. Journal of Marine Systems, 139, pp.139-158.

Umlauf, L. and H. Burchard (2003) A generic length-scale equation for geophysical turbulence models. J. Mar. Res., 6, pp. 235-265.

Valle-Levinson, C. Li, T. Royer, and L. Atkinson (1998) Flow patterns at the Chesapeake Bay entrance. Continental Shelf Research, 18(10), 1157-1177.

Valle-Levinson, A., Reyes, C., Sanay, R., 2003. Effects of bathymetry, friction, and rotation on estuary-ocean exchange. J. Phys. Oceanogr. 33, 2375-2393.

Valle-Levinson, A., K. Holderied, C. Li, and R. J. Chant (2007), Subtidal flow structure at the turning region of a wide outflow plume, J. Geophys. Res., 112, C04004, doi:10.1029/2006JC003746. 
Xu, J., W. Long, J. D. Wiggert, L. W. J. Lanerolle, C. W. Brown, R. Murtugudde, and R. R. Hood, 2011: Climate forcing and salinity variability in Chesapeake Bay, USA. Estuaries and Coasts, 35, 237-261, doi:10.1007/s12237-011-9423-5.

Ye, F., Zhang, Y., Friedrichs, M., Wang, H.V., Irby, I., Shen, J., and Z. Wang (2016) A 3D, cross-scale, baroclinic model with implicit vertical transport for the Upper Chesapeake Bay and its tributaries, Ocean Modelling, vol. 107, 82-96. 10.1016/j.ocemod.2016.10.004.

Yu, H.C., Zhang, Y.J., Jason, C.S., Terng, C., Sun, W., Ye, F., Wang, H.V., Wang, Z. and Huang, H., 2017. Simulating multi-scale oceanic processes around Taiwan on unstructured grids. Ocean Modelling, 119, pp.72-93.

Zeng, X., M. Zhao and R.E. Dickinson (1998) Intercomparison of bulk aerodynamic algorithms for the computation of sea surface fluxes using TOGA COARE and TAO data. J. Clim., 11, pp. 2628-2644.

Zhang, Y., Baptista, A.M., 2008. SELFE: A semi-implicit Eulerian-Lagrangian finiteelement model for cross-scale ocean circulation. Ocean Model. 21, 71-96.

Zhang, Y., Ateljevich, E., Yu, H.-C., Wu, C.H., Yu, J.C.S., 2015. A new vertical coordinate system for a 3D unstructured-grid model. Ocean Model. 85, 16-31.

Zhang, Y., Ye, F., Stanev, E. V, Grashorn, S. (2016a) Seamless cross-scale modelling with SCHISM. Ocean Model. 102, 64-81.

Zhang, Y., Stanev, E.V. and S. Grashorn (2016b) Unstructured-grid model for the North Sea and Baltic Sea: validation against observations, Ocean Modelling, 97, 91-108.

Zhong, L.,Li, M., and Foreman, M.G.G. (2008) Continental Shelf Research, 28, 2565.

\section{Appendix A: Additional model-data comparisons for the SCHISM}

\section{Bay model}

\section{A1. Salinity}

A complete assessment of the vertical structures using the 3D profiles is the most challenging for models. We present in Figure A1 the model-data comparisons of CTD casts at eight representative stations in the main Bay. In these profiles, we used the best match within a 6hour window (i.e. 3 hour before and after the actual time) to account for small phase errors in the model forcing; however, as in Ye et al. (2016), we found that the skill using the actual cast times are generally similar.

The comparisons at the five channel stations from lower Bay to upper Bay demonstrate that the model-data agreement is good in general (Figure A1, a-e). Only marginal deterioration of skill is observed at the upper Bay stations like $\mathrm{CB} 3.3 \mathrm{C}$ as compared to $\mathrm{Ye}$ et 
al. (2016). This deterioration is expected, since the upper Bay domain is smaller and its downstream boundary is at mid-Bay, where the boundary conditions were more accurately specified using observation. In this model, the strong stratification observed at $\mathrm{CB} 3.3 \mathrm{C}$ and CB4.4 is generally well captured, but is under-estimated sometimes in summer low-flow seasons. The northern limit of the saltwater intrusion, as observed at CB3.1, is also accurately simulated by the model.

The profile comparisons at representative shallow shoal stations can be found in Figure A1 (f-h). With adequate resolution used there, the model skill is similar to that in deepchannel stations. This is important, as increasing attention is being focused on these shallow productive areas. The consistency of model results at both channel and shoal stations suggests that the model is able to capture the channel-shoal difference well as a result of accurate representation of underlying bathymetry. Sensitivity runs suggest that the under-estimation of stratification at certain time instances and particularly near the sharp pycnocline may be due to some missing processes in the turbulence model (e.g., mixing due to small-scale internal waves etc).

\section{A2. 1996 survey}

In this section, the dataset from Valle-Levinson et al. (2007)'s survey in 1996 is used to validate the model in the plume region under extreme forcings. The Chesapeake Bay plume is strongly influenced by the Bay outflow, bottom friction and wind, and the offshore extent of the plume is found between the scale predicted by geostrophic dynamics (internal Rossby radius) and the scale predicted by cyclostrophic dynamics (Valle-Levinson et al., 2007). Jiang and Xia (2016) discussed five types of plume structures as regulated by river outflow and wind.

The El Nino event in 1996 is one of the strongest in recent history, and was accompanied by large precipitation events in Feb, Sept, and Nov. 1996 (Figure 6b). The combination of the large outflow and upwelling favorable winds in Nov. 1996 pushes the freshwater plume 90 $\mathrm{km}$ directly offshore (Error! Reference source not found.A2a). The plume configuration roughly corresponds to the second plume type described by Jiang and Xia (2016).

Note that the large offshore extent of the plume (Error! Reference source not found.A2) is relatively rare for Chesapeake Bay, as the plume seldom extends this far offshore due to the combined effects of Coriolis and the prevalent southward shelf current. The southward shelf 
current effectively arrests "upstream" intrusion of the plume, making it attached to the coast along the direction of Kelvin wave propagation (Fong and Geyer, 2002). This is very different from some other large river plumes that regularly spread far offshore (e.g. Columbia River).

Multiple transects near the Bay entrance were surveyed in September and November 1996 by Valle-Levinson et al. $(1998,2007)$ and the datasets serve as valuable information on the 3D structure of the Chesapeake freshwater plume. Here we present comparisons of velocity profiles along a few transects near the entrance collected during the surveys (the exact locations are shown in

Figure 1). The simulated profiles are temporally averaged, corresponding to the 24-hour periods of each cruise (Valle-Levinson et al., 2007). The model generally has a reasonable skill in capturing the complex 3D flow in the plume region (Figure A3). The subtidal flow in Transects 2 and 3 revealed containment of the plume as well as the outflow plume separating from Cape Henry resulting in a recirculation of bay plume there. These features are qualitatively captured by the model as well (Figure A3). The depth mismatches between observation and model in Figure A3, and also in some plots of Figure A1 for CTD casts, are examples of Type I bathymetry errors mentioned in Section 4.

\section{A3. Model assessment on the shelf}

Circulation patterns on the MAB continental shelf are driven by large-scale processes. The equatorward shelf current is the strongest signal on the inner shelf, while the poleward flowing Gulf Stream is dominant near the shelf break in the upper $200 \mathrm{~m}$. The Gulf Stream path veers towards the open ocean near Cape Hatteras where the current begins to transition from a topographically trapped western boundary current to a vigorously meandering free jet. Recent observations suggest that larger variability of this separation points may be a plausible cause for the warming of the MAB and local relative sea-level rise (Andres, 2016; Ezer, 2013). This baroclinic instability creates complex eddies and counter-currents between the Gulf Stream and the shelf currents (Chen et al., 2014).

Instead of showing detailed comparisons of currents and SST in the shelf, we will only discuss the SST comparison here because the HF radar data in this region has some uncertainties. A typical comparison of the monthly averaged SST between the model and the G1SST reanalysis product is shown in Figure A4. The Gulf Stream signature near the 
southeast corner of the domain is reasonably captured. The overall RMSE for all years is $1.4{ }^{\circ} \mathrm{C}$. However, the model occasionally exaggerates the upwelling near Cape Hatteras (not shown), which may be due to the insufficient grid resolution used there (and thus the inherent bathymetric error), or exclusion of Pamlico and Albemarle Sounds in our grid, as the exchange through the inlets of barrier islands between the warmer water inside the Sounds and the colder upwelled water near the coast may help moderate the upwelling. This is left for future research.

Table 1: Sensitivity tests with respect to important model parameters

\begin{tabular}{|c|c|c|c|}
\hline Parameter name & Parameter choices & Bathymetry & Remarks \\
\hline Transport schemes & Upwind; explicit TVD & Original & $\begin{array}{l}\text { Under-predicting intrusion and } \\
\text { stratification, suggesting larger } \\
\text { numerical diffusion }\end{array}$ \\
\hline $\begin{array}{l}\text { Turbulence closure } \\
\text { schemes }\end{array}$ & & Original & Results are similar \\
\hline Time step & s & Original & $\begin{array}{l}\text { Results are similar when below } \\
150 \mathrm{~s} \text {; a time step of } 180 \mathrm{~s} \\
\text { produces more mixing and less } \\
\text { stratification }\end{array}$ \\
\hline $\begin{array}{l}\text { Resolution of the } 1 \\
\text { grid in the main }\end{array}$ & & Original & $\begin{array}{l}\text { Performances are similar when } \\
\text { finer than } 280 \mathrm{~m} \text {, which is the } \\
\text { typical resolution applied in the } \\
\text { baseline model }\end{array}$ \\
\hline $\begin{array}{l}\text { Averaged num } \\
\text { vertical lay }\end{array}$ & $15-35$ & Original & Not sensitive above 24 layers \\
\hline Background diffusivity & $10^{-7}-10^{-3}$ & Original & Not sensitive when $\leq 10^{-6}$ \\
\hline & Drag coefficient; roughness & Original & $\begin{array}{l}\text { A roughness of } 5 \mathrm{~mm} \text { leads to } \\
\text { similar results as the baseline } \\
\text { model with a constant drag } \\
\text { coefficient of } 2.5 \times 10^{-3}\end{array}$ \\
\hline Freshwater inputs & $\begin{array}{l}\text { Watershed model; USGS } \\
\text { gauges }\end{array}$ & Original & Mostly similar salinity results \\
\hline Wind forcing & $\begin{array}{l}\text { Original NARR; hybrid } \\
\text { (NARR+NOAA obs) }\end{array}$ & Original & Mostly similar results \\
\hline Implicitness factor & $0.51-1$ & Original & Similar results \\
\hline Ocean B.C. for salinity & Climatology; HYCOM & Original & $\begin{array}{l}\text { Mostly similar; HYCOM B.C. } \\
\text { occasionally leads to larger } \\
\text { errors }\end{array}$ \\
\hline
\end{tabular}




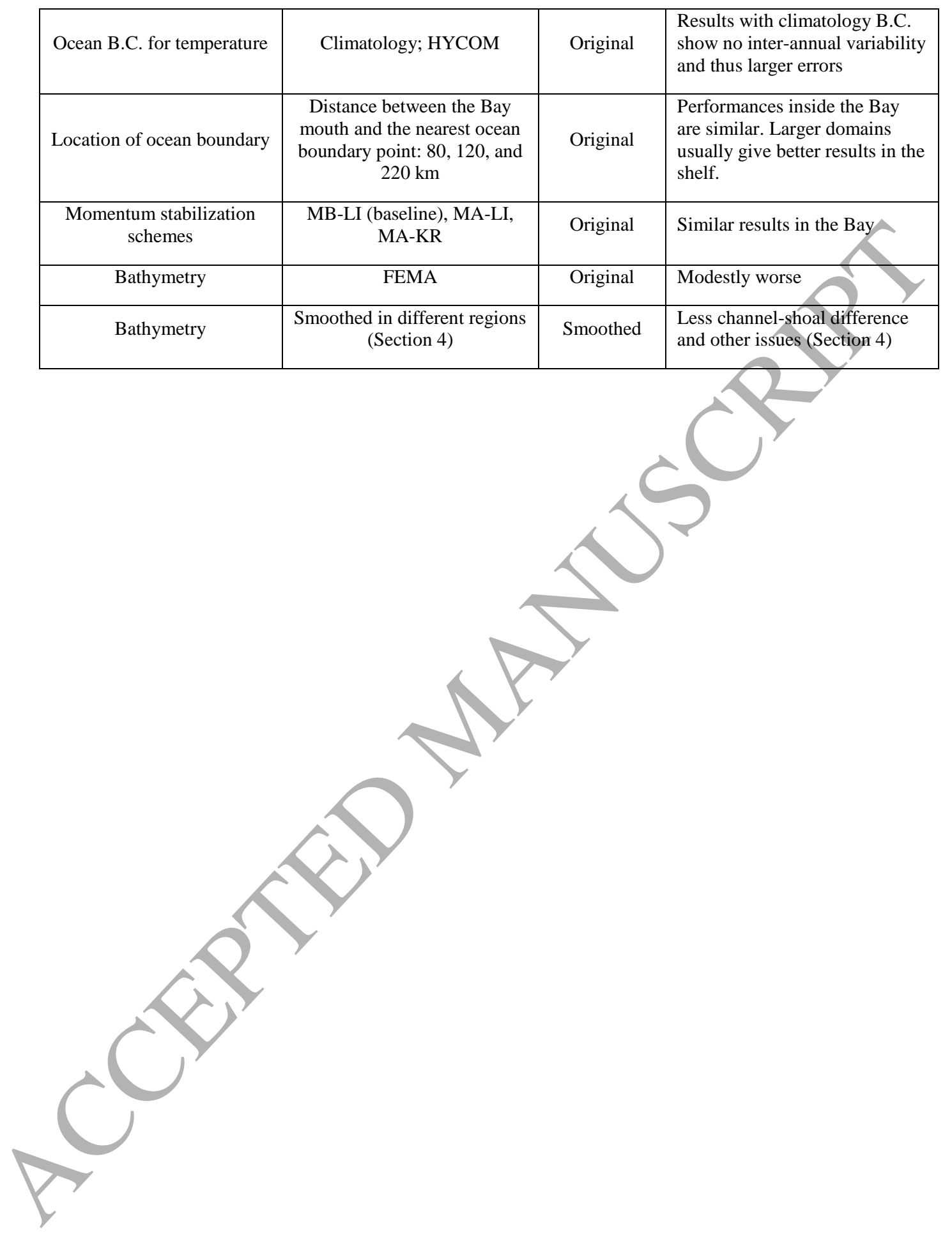

